\title{
The Bias Ratio As A Hedge Fund Fraud Indicator: An Empirical Performance Study Under Different Economic Conditions
}

Francois van Dyk, UNISA, South Africa

Gary van Vuuren, North-West University, South Africa

André Heymans, North-West University, South Africa

\begin{abstract}
The Sharpe ratio is widely used as a performance evaluation measure for traditional (i.e., long only) investment funds as well as less-conventional funds such as hedge funds. Based on meanvariance theory, the Sharpe ratio only considers the first two moments of return distributions, so hedge funds - characterised by complex, asymmetric, highly-skewed returns with non-negligible higher moments - may be misdiagnosed in terms of performance. The Sharpe ratio is also susceptible to manipulation and estimation error. These drawbacks have demonstrated the need for augmented measures, or, in some cases, replacement fund performance metrics. Over the period January 2000 to December 2011 the monthly returns of 184 international long/short (equity) hedge funds with investment mandates that span the geographical areas of North America, Europe, and Asia were examined. This study compares results obtained using the Sharpe ratio (in which returns are assumed to be serially uncorrelated) with those obtained using a technique which does account for serial return correlation. Standard techniques for annualising Sharpe ratios, based on monthly estimators, do not account for serial return correlation - this study compares Sharpe ratio results obtained using a technique which accounts for serial return correlation. In addition, this study assess whether the Bias ratio supplements the Sharpe ratio in the evaluation of hedge fund risk and thus in the investment decision-making process. The Bias and Sharpe ratios were estimated on a rolling basis to ascertain whether the Bias ratio does indeed provide useful additional information to investors to that provided solely by the Sharpe ratio.
\end{abstract}

Keywords: Hedge Funds; Bias Ratio; Fraud; Risk Management; Sharpe Ratio

\section{INTRODUCTION}

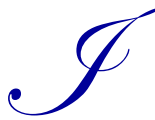

nstitutional investors and wealthy individuals have for a long time been interested in hedge funds as alternative investments to traditional asset portfolios, while the public's interest in the hedge fund industry has also increased through spectacular hedge fund activities, such as the collapse of Long Term Capital Management (LTCM) in the late 1990's. Since the early 1990's, hedge funds have become an increasingly popular asset class as global investment rose from US $\$ 50 \mathrm{bn}$ in 1990 to US $\$ 2.2 \mathrm{tn}$ in early 2007 (Barclayhedge, 2013). In March 2012, long/short equity funds accounted for the largest portion - 23\% - of the industry by assets (Citi, 2012). The hedge fund industry posted its sturdiest gains, in terms of asset flows and performance, between 2003 to 2007 where after the financial crisis significantly curtailed growth. However, industry growth reversed, declining to US $\$ 1.4$ tn by April 2009 due to substantial investor redemptions and performance-based declines (Eurekahedge, 2012). In April 2013, total assets under management (AUM) for the hedge fund industry had risen to only US\$1.9tn (Eurekahedge, 2013) with growth relatively flat, as shown in Figure 1. 


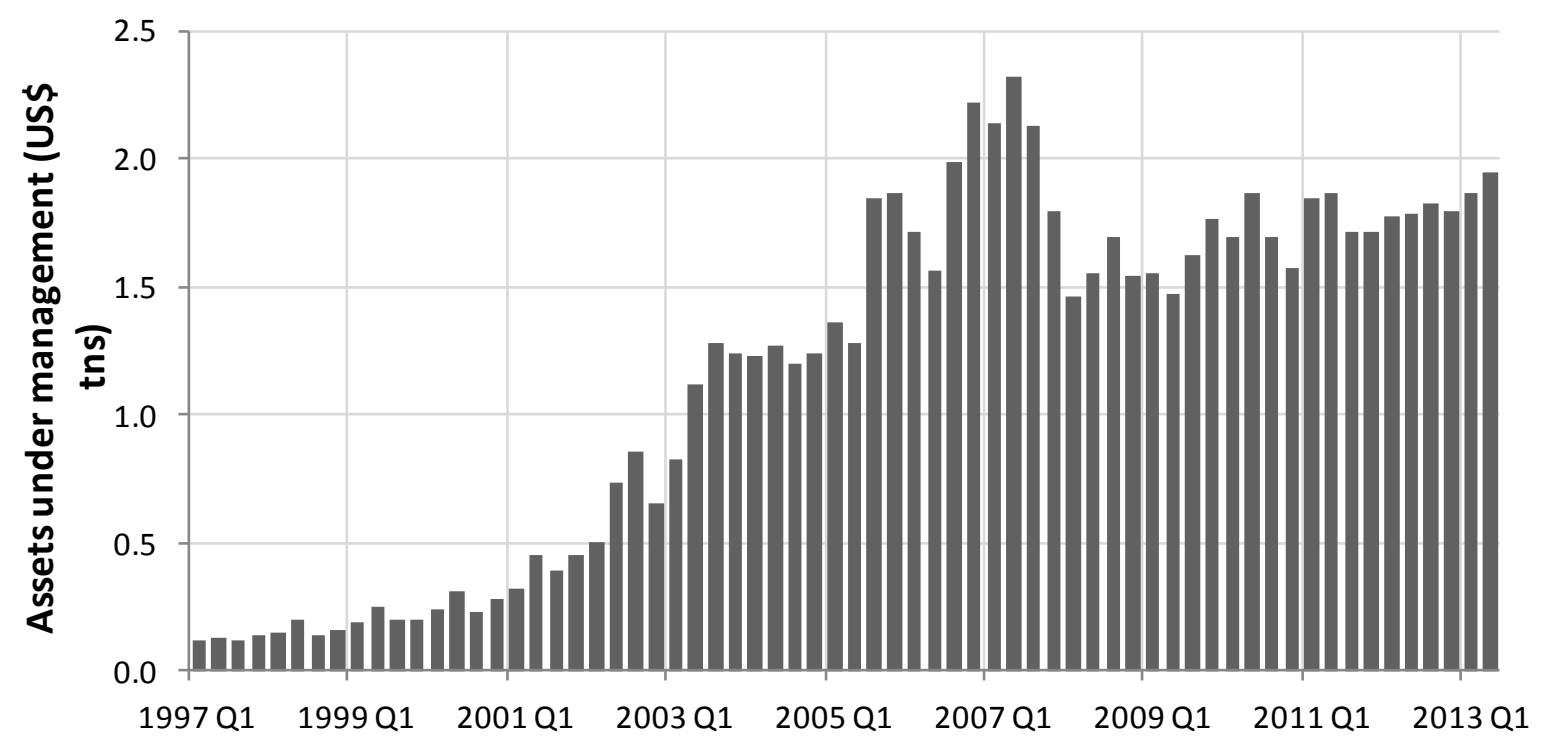

Figure 1: Hedge Funds' Assets under Management (US\$Tns), 1997 to Quarter 2 of 2013 Source: Barclayhedge (2013)

Although most comparisons of hedge fund returns concentrate exclusively on total return values, comparing funds with different expected returns and risks in this manner is meaningless. The combination of return and risk into a risk-adjusted number is one of the key tasks of performance measurement (Lhabitant, 2004). The hedge fund industry has adopted a number of risk-adjusted ${ }^{1}$ performance measures (some of which are also commonly used in traditional funds) such as the Sharpe and Treynor ratios, Jensen alpha, $M^{2}$, and downside (risk) measures such as the Sortino ratio and Value-at-risk ( $\mathrm{VaR})$.

The Sharpe ratio is the metric of choice amongst hedge funds and also the most commonly used measure of risk-adjusted performance (Lhabitant, 2004; Opdyke, 2007; Schmid \& Schmidt, 2007). Proposed by Sharpe as the "reward-to-variability" ratio as a mutual fund comparison tool (see, Sharpe, 1966, 1975, 1994) the ratio is both conceptually simple and rich in meaning, providing investors with an objective, quantitative measure of performance. It enjoys widespread use and numerous interpretations, but it also has its drawbacks, which will be discussed in Section 2.1. Among others, volatility measures are generally unsuitable for dealing with asymmetric return distributions (Lhabitant, 2004).

Return performance is, however, also a key objective for hedge funds, and the hedge fund universe showed an annual return of $8.82 \%$ from 1995 until 2003 compared to an annual return of 12.38\% for the S\&P500 (Malkiel \& Saha, 2005). More recently, in 2011 the hedge fund industry reported a $4.6 \%$ performance loss, although most of the losses occurred in the third quarter when global equity markets fell by approximately 17\% (TheCityUK, 2012). Between 2002 and 2012 average annual returns for hedge funds were 6.3\% (TheCityUK, 2012) compared with 5.7\% for U.S. bonds, ${ }^{2} 7.8 \%$ for global bonds, ${ }^{3}$ and $6.0 \%$ for the S\&P500. The hedge fund industry posted its worst annual performance in $2008(-20 \%)$, its worst since 1990 while total fund liquidations rose to around 775 in 2011 , an increase of $4 \%$ from 743 in the previous year. Although the total number of funds rose to 9,523 in 2011 this number still fails to eclipse the pre-crisis peak at the end of 2007 of 10,096 funds (Clarke, 2012). According to figures from Hedge Fund Research (HFR), hedge fund launches and total fund numbers have at March 2012 still not returned to their pre-financial crisis levels (Clarke, 2012). In terms of the industry's asset size, AUM declined $27 \%$ in 2008 to US\$1.4tn (Roxburgh et al., 2009) and even further in March 2009 to US\$1.29tn (Eurekahedge, 2010), echoing both asset withdrawals and investment losses.

\footnotetext{
${ }^{1}$ Usually performance indicators that combine the returns with the risk of the fund (Botha, 2007).

${ }^{2}$ U.S. bonds as measured by the Barclays U.S. Aggregate Bond Index.

${ }^{3}$ Global bonds as measured by the JP Morgan Global Government Bond Index (unhedged).
} 
Investor withdrawals following the financial crisis (when it became clear that hedge funds had not "hedged" well at all) contributed to poor performance. This has led to a high attrition rate (Brown et al., 1999, 2001a, 2001b; Liang, 1999) which has also increased significantly over time. Only 90.9\% of funds that were alive in 1996 were still alive in 1999, while this declined to 59.5\% in 2001 (Kat \& Amin, 2001). Furthermore, Kaiser and Haberfelner (2012) found that the attrition rate for hedge funds has nearly doubled since the financial crisis. In the highly competitive world of fund performance, the reporting of monthly returns can exacerbate investor outflows, halt them, reverse them, or increase them - depending on the reported figures. The incentive to exaggerate or misrepresent fund performance is strong (see, e.g., Feng, 2011; Agarwal \& Naik, 2011; Goetzmann et al., 2007; Bollen \& Pool, 2009). Also as investors pay high fees, typically in the vicinity of a $2 \%$ management fee and a $20 \%$ performance fee, performance evaluation and an accurate performance evaluation methodology are of vital importance to investors (Lopez de Prado, 2013).

It is possible that the risks that hedge funds face are not measured sufficiently accurately, measures currently employed are inadequate or they are sometimes misrepresented. Consideration of new measures, in addition to the Sharpe ratio, to augment hedge fund risk (and risk-adjusted return) measurement have long been debated (e.g., Perello, 2007; Wiesinger, 2010). One such measure is the Bias Ratio, a practical measure for detecting potentially suspicious fund returns (Abdulali, 2006).

This study evaluates whether the Bias ratio should augment the use of the Sharpe ratio when evaluating hedge fund risk and in the investment decision-making process. Not only does the Bias ratio provide information over and above that given by the Sharpe ratio, but the latter is ill-suited to hedge funds (which exhibit complex, asymmetric, and highly-skewed return distributions).

The remainder of this paper is structured as follows: Section 2 presents an overview of the existing literature governing fund performance, as well as an overview of both alternative (risk-adjusted) performance measures and the influence on the Sharpe ratio of illiquidity and smoothing. Section 3 introduces the technical details of the Bias ratio, discusses other fraud measures as well as the data employed, and concludes with a realworld application of the Bias ratio to a known fraud ${ }^{5}$ to validate its applicability and robustness. Section 4 presents the analysis and results along with some comparative summary statistics and Section 5 concludes.

\section{LITERATURE STUDY}

\subsection{Inadequacy of Sharpe Ratio}

The Sharpe ratio is one of the most commonly cited statistics in financial analysis and the metric of choice amongst hedge funds, particularly as a measure of risk-adjusted performance (Koekebakker \& Zakamouline, 2008; Lhabitant, 2004; Lo, 2002; Opdyke, 2007; Schmid \& Schmidt, 2007). Also known as the risk-adjusted rate of return (Sharpe, 1966, 1975, 1992, 1994; van Vuuren et al., 2003), it is calculated using:

$S R=\frac{r_{p}-r_{f}}{\sigma \sqrt{T}}$

where $r_{P}$ is the cumulative portfolio return measured over $T$ months, $r_{f}$ is the cumulative risk-free rate of return measured over the same period, and $\sigma$ is the monthly portfolio volatility (risk). Despite its widespread use, the measure does, however, have some weaknesses, especially within the hedge fund context.

Expected returns and volatilities are non-observable quantities so they must be estimated. The Sharpe ratio is thus determined with inevitable estimation errors. Lo (2002) argued that little attention has been given to the statistical properties of the Sharpe ratio given that the accuracy of its estimators rely on the statistical properties of returns, and that these may be very different among portfolios, strategies, and over time. By this Lo (2002) concludes that the performance of more volatile investment strategies is more difficult to determine than less volatile strategies. Since hedge funds are generally more volatile than more traditional investments (Ackermann et al., 1999;

\footnotetext{
${ }^{4}$ Attrition rate is the liquidation rate of funds.

${ }^{5}$ The Madoff fraud case is used in the application of the Bias ratio.
} 
Liang 1999), Sharpe ratio estimates for hedge funds are likely to be less accurate. Numerous statistical tests that provide for Sharpe ratio comparisons between two portfolios have been proposed by Gibbons, Ross, and Shanken (1989), Jobson and Korkie (1981), Lo (2002), and Memmel (2003). However, the unavailability of multiple Sharpe ratio comparisons has led to alternative approaches (e.g., Ackermann et al., 1999; Maller \& Turkington, 2002). It is clear that a more refined approach of interpreting Sharpe ratios is necessary and that such an approach should possibly consider information concerning the investment style or strategy and also the market environment in which the returns are generated. In addition, it has also been demonstrated that the Sharpe ratio is prone to manipulation (see, e.g., Goetzmann et al., 2002, 2007; Spurgin, 2001).

Brooks and Kat (2002) found that hedge fund indices exhibit low skewness and high kurtosis, while Scott and Horvath (1980) found that investors prefer high first and third moments (mean and skewness) and low second and fourth moments (standard deviation and kurtosis). Asymmetric distributions influence the validity of volatility as a risk measure, which in turn also impacts the accuracy of the Sharpe ratio. Volatility measures only the dispersion of returns around their historical average and given that positive and negative deviations from the average are penalised in an equal manner in the calculation, the concept only makes sense for symmetrical distributions (Lhabitant, 2004). In practice most return distributions are neither normal nor symmetrically distributed, thus even when two investments have the same mean and volatility, they may have significantly different higher moments. This is particularly true for strategies involving dynamic trading, buying and selling options, and active leverage management (Lhabitant, 2004) - all strategies employed by hedge funds. The return distributions of such strategies are highly asymmetric and possess "fat tails," which in turn render volatility less meaningful as a measure of risk. From an investor's perspective the relevance of the dispersion of returns around an average has been questioned, as most investors perceive risk as a failure to achieve a specific goal such as a benchmark rate (Lhabitant, 2004; Vanguard, 2012). In this situation, risk is only considered as the downside of the return distribution and not the upside: volatility does not capture this difference (Lhabitant, 2004). Investors are also more adverse to negative deviations than to positive deviations of the same magnitude (Lhabitant, 2004).

The Sharpe ratio is based on the mean-variance framework, which employs the CAPM methodology under which the appropriate measure of risk is represented by $\beta$ :

$$
\begin{aligned}
\beta_{P} & =\frac{\operatorname{Cov}\left(r_{p}, r_{m k t}\right)}{\operatorname{Cov}\left(r_{m k t}, r_{m k t}\right)} \\
& =\frac{\operatorname{Cov}\left(r_{p}, r_{m k t}\right)}{\operatorname{Var}\left(r_{m k t}\right)}
\end{aligned}
$$

where $r_{p}$ and $r_{m k t}$ are the portfolio and market returns, respectively.

Strong assumptions underlie the CAPM; e.g., (i) returns are normally distributed and (ii) investors care only about the mean and variance of returns, so upside and downside risks are viewed with equal dislike (Leland, 1999). These assumptions seldom hold in practice: even if the underlying assets' returns are normally distributed, the returns of portfolios that contain options on these assets, or use dynamic strategies will not be (Leland, 1999).

Hedge funds generally employ dynamic investment strategies, with accompanying dynamic risk exposures, and these have important implications for investors who seek to manage the risk/reward trade-offs of their investments (Chan et al., 2005). For this reason, hedge fund performance is often summarised with multiple statistics. ${ }^{6}$ While $\beta$ is an adequate risk measure for static investments, there is no single measure capturing the risks of a dynamic investment strategy (Chan et al., 2005). Linear performance measures can often not capture the dynamic trading strategies that several hedge funds pursue (Agarwal \& Naik, 2004) whilst hedge funds employ a range of trading strategies. Analysing all hedge funds using a singular performance measurement framework that does not consider the characteristics of the specific strategies is of limited value. Hedge fund style specific performance measurement models or measures are required in order to capture the differences in management style (Agarwal \& Naik, 2004; Fung \& Hsieh, 2001, 2004).

${ }^{6}$ e.g., mean, standard deviation, Sharpe ratio, market beta, Sortino ratio, maximum drawdown, etc. (Chan et al., 2005). 
A large number of equity-orientated hedge fund strategies bear significant (left-tail) risk that is ignored by the mean-variance framework ${ }^{7}$ (Lhabitant, 2004).

\subsection{Alternative Risk Performance Measures}

The drawbacks of volatility as a measure of risk clarify why alternative risk measures have been sought (Lhabitant, 2004). Many alternative measures replace the Sharpe ratio's denominator (volatility) by an alternative measure of risk. For example, Sortino and Price (1994), as well as Ziemba (2005), substitute standard deviation by downside-deviation. Gregoriou and Gueyie (2003) propose a modified Sharpe ratio as an alternative measure specifically for hedge fund returns by using a modified Value-at-Risk (VaR) instead of standard deviation as the denominator. ${ }^{8}$ Dowd (2000) replaces standard deviation by a VaR measure, while conditional VaR may also be used. The Stutzer index is based on the behavioural hypothesis that investors aim to minimise the probability that the excess returns over a given threshold will be negative (Stutzer, 2000). The Omega ratio expresses the ratio of the gains with respects to a chosen threshold to the loss with respect to the same threshold (Shadwick \& Keating, 2002). Kaplan and Knowles (2004) introduced the Kappa measures which generalises the Sortino and Omega ratios, while Koekebakker and Zakamouline (2008) derive a formula for a natural extension of the Sharpe ratio that considers the skewness of the distribution. ${ }^{9}$

These alternative performance measures, however, lack solid theoretical underpinnings (considering the Sharpe ratio is based on the expected utility theory) (Koekebakker \& Zakamouline, 2008) and do not allow accurate ranking of portfolio performance since ranking based on these measures depends significantly on the choice of threshold. In addition, most of these measures take into account only downside risk, while the upside potential is not considered.

\subsection{Influence of Illiquidity and Return Smoothing on Sharpe Ratio}

Illiquidity and (return) smoothing also have an impact on the Sharpe ratio. Alternative investment returns are often highly serially correlated, due mainly to illiquidity exposure and smoothed returns, although several potential explanations exist (Chan et al., 2005; Getmansky et al., 2004). Serial correlation is thus used as a proxy for liquidity. In most cases, serial correlation in hedge fund returns is the result of illiquid component securities (Getmansky et al., 2004), which can include securities not actively traded and for which market prices are not always readily available. In such instances, the hedge fund manager has considerable discretion in marking the portfolio's value (to arrive at the fund's net asset value (NAV)), while this leads to the reported returns of funds containing illiquid securities appearing to be smoother than true economic returns, ${ }^{10}$ and as a consequence this will convey a downward bias on the estimated return variance and yield positive serial return correlation. In the hedge fund context serial correlation is thus mostly likely the outcome of illiquidity exposure, and while non-synchronous trading ${ }^{11}$ could be one symptom or by-product of illiquidity, it is not the only aspect of illiquidity that affects hedge fund returns. Bisias et al. (2012), however, found that funds that invest in highly liquid securities (e.g., equity funds) have autocorrelations near zero. Funds with high serial autocorrelations indicate returns smoothing although market inefficiencies, time-varying expected returns and leverage and incentive fees with high-water marks could also be the cause (Getmansky et al., 2004). Cao et al. (2013) estimated that $24 \%$ of hedge fund reported return autocorrelation is due to managerial discretion in reporting returns, while the underlying assets are responsible for the remaining $76 \%$ of autocorrelation. The amount of autocorrelation due to managerial discretion was found to be higher for funds with greater barriers to liquidity ${ }^{12}$ as measured by the length of both the redemption notice period and the lockup period (Cao et al., 2013).

\footnotetext{
${ }^{7}$ These left-tail risks originate from hedge fund strategies that exhibit payoffs resembling a short position in a put option on the market index (Lhabitant, 2004).

${ }^{8}$ The standard VaR only considers mean and standard deviation while modified VaR takes both the mean and standard deviation as well as skewness and excess kurtosis into consideration.

${ }^{9}$ This ratio is denoted as the adjusted for skewness Sharpe ratio (ASR).

${ }^{10}$ Returns that fully reflect all available market information (in relation to those securities).

${ }^{11}$ This trading phenomenon demotes to security prices recorded at different times, but being incorrectly treated as if they were recorded simultaneously.

${ }^{12}$ In this context liquidity refers to the ease or difficulty with which an investor can make or redeem an investment in the fund (Cao et al., 2013).
} 
In terms of valuation behaviour, Cici et al., (2013) found that a negative coefficient on past holding return exists. This suggests that following lower past returns, a tendency to overvalue the portfolio exists and alternatively, following high past returns, a tendency to undervalue the portfolio exists. Such behaviour hints that part of the valuation behaviour is directly motivated by incentives related to performance considerations. The nature of hedge fund compensation structures which is commonly linked to performance statistics (Do et al., 2005) could encourage returns manipulation through "smoothing"; i.e., marking portfolios to less than their actual value in months with large positive returns so as to create a "cushion" for other months with lower returns. Just under half of hedge fund managers were found to modify their data (Patton et al., 2012). The data modifications included not only performance improvements, but also downward performance adjustments depending on either relevant performance fee levels or high-water marks. Practices such as return-smoothing practices yield a more consistent set of returns over time, with lower volatility, and ultimately a higher Sharpe ratio, but also high serial correlation. The more illiquid the portfolio, the more leeway the manager has in marking its value and smoothing returns, while also creating serial correlation in the process. Cici et al. (2013) showed that valuation deviations are related to stock characteristics and specifically that positions corresponding to highly illiquid stocks display more valuation deviations. Cici et al. (2013) also found that a significant fraction of deviations exist among highly liquid positions, suggesting that illiquidity alone cannot explain observed valuation discrepancies. ${ }^{13}$ It is therefore imperative that investors know the NAV calculation methodology used as there is a tendency for managers to "manage" optimally their monthly NAV in order to smooth their returns, which in turn also enables a fund to hide risk (Lhabitant, 2004). This problem is particularly severe in two categories of hedge funds namely; (i) hedge funds holding illiquid securities or securities that are difficult to price, ${ }^{14}$ and (ii) US onshore limited partnerships. ${ }^{15}$ Valuation practices have been found which show no consistent market practice across hedge funds when numerous quotes were available (Lhabitant, 2004). Approximately 50\% of fund respondents used an average quote, 36\% used subjective judgement, $7 \%$ used the median quote, and $7 \%$ eliminated the high and low prices and then averaged the remaining quotes. The significance of smoothed returns and serial correlation is considered in greater detail in Getmansky et al. (2004) and Lo (2002).

Additional bias in reported Sharpe ratios occurs when monthly Sharp ratios are annualised by multiplying by $\sqrt{12}$. This is the correct procedure if the returns are independently and identically distributed (IID), but for nonIID returns, an alternative procedure that accounts for serial correlation must be used (Lo, 2002). It is, however, important to take illiquidity and smoothed returns into account when evaluating the performance of hedge funds (Getmansky et al., 2004).

Conditional serial correlation can, therefore, be considered as an indicator of (possible) fraud, as when true returns are independently distributed and a manager fully reports gains but delays reporting losses the reported returns will feature conditional serial correlation (Bollen \& Pool, 2008).

An additional measure that should be considered by investors might include a measure that detects fraudulent activity or has the ability to identify a heightened risk of fraud by hedge funds. One such measure is the Bias ratio, which is introduced in the next section.

\section{METHODOLOGY AND DATA}

\subsection{The Bias Ratio}

The Bias ratio, introduced by Abdulali (2006), is a metric devised to highlight possible fund manipulation and thus a practical method for filtering suspicious funds. The measure is similar to Benford's law, ${ }^{16}$ a comparable leading digits mathematical theory that provides a distinctive method of data analysis (Nigrini, 1999). This method, used by forensic accountants, may be employed to establish the normal level of number duplications in data sets,

\footnotetext{
${ }^{13}$ Cici et al. (2013) found that roughly $7 \%$ of all equity positions are valued at different prices from closing prices as reported to the Centre of Research in Security Prices (CRSP).

${ }^{14}$ Marking to market of these assets is quite often difficult due to either small trading volumes and/or the unavailability of daily true economic traded prices.

${ }^{15}$ As the majority of these funds value their own portfolios.

${ }^{16}$ Benford's law is named for physicist Frank Benford (1938).
} 
which thus makes it possible to identify both abnormal digit and number occurrences. Benford's law can be used to identify irregularities which might indicate possible error, fraud, manipulative bias, or other inefficiency (Nigrini \& Mittermaier, 1997; Raimi, 1976).

The Bias ratio exposes possible fund return manipulation and can thus be used as an indicator (but not ultimate proof) of fraudulent activity. The Bias ratio is similar to a test for randomness, as it is a mathematical technique that identifies abnormalities in the distribution of returns. Bollen and Pool (2012) establish a significant relationship between a variety of suspicious return patterns and the incidence of fraudulent activity and other regulatory violations. The metric calculates the ratio of the frequency of positive returns to the frequency of negative returns to within one standard deviation of the observed return distribution; i.e., it investigates the return distribution's degree of symmetry, by analysing the fund returns to measure how far the returns are from an unbiased distribution. The Bias ratio for a highly liquid fund or portfolio such as an equity index should thus be close to one, while the Bias ratio of a fund that holds highly illiquid securities will be $\gg 1$. The latter occurs when bias is introduced where fund managers have discretion in the valuation process. It is difficult to smooth returns for funds dealing with high liquidity due to valuation set by readily available market prices. Conversely, a high (or increasing) Bias ratio (when dealing in more illiquid securities) is not in itself proving return manipulation, as by nature illiquid securities have a propensity to deliver smoother returns (Le Marois, 2008). This is the case even with an objective valuation process, although a high (or increasing) Bias ratio may still prove that funds dealing in very illiquid securities actively manipulate their returns ${ }^{17}$ (Le Marois, 2008). It is, however, important to be aware that return smoothing does not necessarily imply unfair NAV manipulation; it could simply mean that the value is based on an (in-house) subjective rather than an objective process of valuation.

Illiquid securities are often associated with serial correlation of returns, so serial correlation or a very high Sharpe ratio can be taken as a warning indicator, but not necessarily as a conclusive and final verdict. Results statistically support the Bias ratio as an indicator of return smoothing, as well as a statistical relationship between the liquidity of different asset strategies and their Bias ratios (Le Marois, 2008). The Bias ratio can thus assist in detecting NAV manipulation (i.e., subjective pricing) while also being able to recognise the presence of illiquid securities where they should not exist, but the ratio must be interpreted in line with the liquidity of the strategy being observed. ${ }^{18}$ The Bias ratio makes a good case as a due-diligence tool for the (diligent) investor as it serves as a warning flag which can then lead to further investigation.

\subsection{Other Fraud Measures}

Bollen and Pool (2012) identified (ex-ante) a heightened risk of hedge fund fraud using a collection of quantitative algorithms or performance flags, which require only a time-series of returns. The performance flags used were based on suspicious patterns in reported fund returns consistent with fraudulent activity. Bollen and Pool $(2008,2009)$ present conditional serial correlation and discontinuity analysis ${ }^{19}$ using time series analysis and Gaussian kernel density estimations, respectively.

In (2009) extends a manipulation-proof performance measure (MPPM) (Goetzmann et al., 2007) to a measure for detecting suspicious funds. The measure is derived from the MPPM ${ }^{20}$ which is derived from a utility function that bores a fund's implied risk aversion. The method is still to be thoroughly scrutinised.

The Doubt Ratio (DR) is a relatively new measure based on MPMM which detects funds with manipulated performance scores or misreported returns (Brown et al., 2010).

\footnotetext{
${ }^{17}$ This practice introduces a severe violation in terms of risk transparency.

${ }^{18} \mathrm{~A}$ Bias ratio far from the median value, observed for a particular strategy, should be considered as abnormal.

${ }^{19}$ Bollen and Pool's (2009) discontinuity approach revolves around the discontinuity of the observed return distribution around zero by comparing it to the expected distribution which is based on Gaussian kernel estimation.

${ }^{20}$ The MPPM is a decreasing function of the relative risk aversion, given the risk-free rate and the observed returns.
} 


\subsection{Data}

This study uses the 26,496 monthly returns, net of management and performance fees, from 184 'live' individual ${ }^{21}$ hedge funds from a Eurekahedge database data extract between January 2000 and December 2011. Funds without a complete monthly return history for the chosen period were not considered. Monthly returns were chosen as hedge funds universally report performance figures on this basis and it is compatible with investors' month-end, holding-period return. The data do not suffer from survivorship, backfilling, or sampling biases, while selection bias cannot be addressed as it would require access to returns from hedge funds that decide not to report.

Table 1 presents the summary statistics, in monthly percentages, for the hedge fund returns as well as some other relevant information. The $t$-statistics indicate that the mean returns are significantly different from 0 at the 5\% significance level for all funds. Also 29 of the 184 funds (15.8\%) exhibit normal distributions at the 5\% significance level, using the Jarque-Bera (JB) test, while the remaining 155 funds (84.2\%) have non-normal distributions.

Table 1: Summary Statistics for Long/Short Equity Hedge Funds

\begin{tabular}{|c|c|c|c|c|c|}
\hline & All Funds & North America & Europe & Asia & Global \\
\hline No. of funds & 184 & 85 & 38 & 15 & 46 \\
\hline Sample size & 26496 & 12240 & 5472 & 2160 & 6624 \\
\hline Mean Age (years) & 15.8 & 16.5 & 14.3 & 14.4 & 16.1 \\
\hline Mean Size (US\$m) & 188 & 143 & 145 & 87 & 346 \\
\hline \multicolumn{6}{|l|}{ Return Statistics } \\
\hline$\mu$ & 0.66 & 0.76 & 0.55 & 0.34 & 0.66 \\
\hline$t(\mu=0)$ & 22.48 & 16.14 & 11.49 & 3.92 & 10.64 \\
\hline$\sigma$ & 4.8 & 5.2 & 3.5 & 4.0 & 5.1 \\
\hline Median & 0.6 & 5.2 & 0.6 & 4.0 & 0.6 \\
\hline Min & -56.7 & -56.7 & -20.0 & -22.4 & -54.7 \\
\hline Max & 76.2 & 76.2 & 29.6 & 19.2 & 39.8 \\
\hline Skewness & 0.75 & 1.14 & 0.49 & -0.15 & 0.05 \\
\hline Kurtosis & 18.4 & 22.3 & 10.0 & 4.9 & 9.6 \\
\hline$\rho_{1}$ & 0.29 & 0.21 & 0.74 & 0.43 & 0.21 \\
\hline$\rho_{2}$ & 0.03 & 0.15 & 0.59 & 0.31 & 0.23 \\
\hline$\rho_{3}$ & 0.02 & 0.01 & 0.55 & 0.29 & 0.21 \\
\hline$p$-value of LB-Q & 0.00 & 0.01 & 0.00 & 0.00 & 0.01 \\
\hline
\end{tabular}

The Ljung-Box Q-statistic measures the overall significance of the first $k$ autocorrelation coefficients, and is asymptotically $\chi_{k}^{2}$ under the null hypothesis of no autocorrelation.

All the funds are categorised as long/short equity (strategy) funds. This was preferred as it is the largest among hedge funds, comprising 35\% of the industry (Brown et al., 2009). All funds are mandated only in highly liquid markets: mandates in developing markets were omitted from the sample. This ensured that funds are equity funds holding liquid instruments. It can be assumed that all securities held have readily available prices and that no subjective valuations are necessary. On average, first-order return autocorrelations $\left(\rho_{1}\right)$ of all but two geographical areas are $\leq 0.30-$ an indication of liquidity (Getmansky et al., 2004). Also, the near zero levels of autocorrelation are consistent with those found by Bisias et al. (2012) for liquid securities such as equity funds.

Table 2 presents a breakdown of the representative geographical mandates of the funds as well as the relevant risk-free rate proxies accordingly used. Data on the risk-free rates were sourced from the Federal Reserve Bank of St. Louis (FRED) and Bloomberg.

\footnotetext{
${ }^{21}$ Meaning not fund of funds, which are funds holding a portfolio of other investment funds, or commodity trading advisors (CTA), but funds that invest directly in securities.
} 


Table 2: Breakdown of Geographical Mandates of Funds \& Risk-Free Rate Proxies
\begin{tabular}{|l|c|c|}
\hline Geographical Mandate & \# funds & Risk-Free Rate Proxy \\
\hline North America* & $85(46 \%)$ & 10 -year Treasury bond rate (US) \\
\hline Europe & $38(21 \%)$ & 10 -year Treasury bond rate (Germany) \\
\hline Asia & $15(8 \%)$ & 10 -year Treasury bond rate (Japan) \\
\hline Global & $46(25 \%)$ & JPMorgan Global Government Bond Index \\
\hline
\end{tabular}

* Includes one Canadian fund (RFR = 10-year Treasury bond rate (Canada)).

The German 10-year Treasury bond rate as the risk-free rate proxy for the European geographical area is generally accepted ${ }^{22}$ (Damodaran, 2008), although a number of other options exist.

Although hedge funds (specifically equity long/short funds), are absolute investments, they are also commonly compared with passive benchmark ${ }^{23}$ indices. $^{24}$ The data on the passive market benchmark indices were collected from Bloomberg, while the data on the hedge fund benchmark indices were sourced from Eurekahedge, Hedge Fund Research (HFR) and Barclayhedge. Table 3 presents the market and hedge fund benchmark indices used.

Table 3: Market and Hedge Fund Benchmark Indices

\begin{tabular}{|c|c|c|}
\hline Benchmark Market Indices & \multicolumn{2}{|c|}{ Region specific } \\
\hline S\&P500, S\&P TSX* & \multicolumn{2}{|c|}{ North America } \\
\hline DAX & \multicolumn{2}{|c|}{ Europe } \\
\hline Nikkei 225 & \multicolumn{2}{|c|}{ Asia } \\
\hline MSCI World Index & \multicolumn{2}{|c|}{ Global } \\
\hline Benchmark Hedge Fund Indices & Region specific & Style specific \\
\hline Eurekahedge North America Long/short Equities Index & North America & Long/short Equity \\
\hline
\end{tabular}

Table 4 presents the summary return statistics for the market and hedge fund benchmark indices, for the period January 2000 until December 2011. These statistics are drawn from the monthly returns with the monthly means and standard deviations in percentages.

Table 4: Summary Statistics for Market and Hedge Fund Benchmark Indices

\begin{tabular}{|c|c|c|c|c|c|c|}
\hline & S\&P500 & DAX & S\&P TSX & Nikkei 225 & Global Index $^{+}$ & L/S HF Index ${ }^{*}$ \\
\hline Sample size & 144 & 144 & 144 & 144 & 144 & 144 \\
\hline$\mu$ & 0.004 & 0.12 & 0.35 & 0.39 & 0.28 & 0.76 \\
\hline$t(\mu=0)$ & 0.01 & 0.21 & 0.92 & 0.81 & 0.06 & 3.78 \\
\hline$\sigma$ & 4.71 & 6.72 & 4.55 & 5.80 & 4.90 & 2.4 \\
\hline Median & 0.60 & 0.73 & 1.01 & 0.13 & 1.17 & 0.99 \\
\hline Min & -16.9 & -25.4 & -16.9 & -23.8 & -25.48 & -6.5 \\
\hline Max & 10.8 & 21.4 & 11.2 & 12.9 & 14.06 & 10.6 \\
\hline Skewness & -0.43 & -0.52 & -0.86 & -0.53 & -1.42 & 0.01 \\
\hline Kurtosis & 3.66 & 4.88 & 4.58 & 3.89 & 5.16 & 4.86 \\
\hline$\rho_{1}$ & 0.13 & 0.07 & 0.22 & 0.12 & 0.31 & 0.20 \\
\hline$\rho_{2}$ & -0.07 & -0.06 & 0.07 & 0.06 & 0.03 & 0.04 \\
\hline$\rho_{3}$ & 0.12 & 0.10 & 0.06 & 0.11 & 0.19 & 0.04 \\
\hline$p$-value of LB-Q & 0.10 & 0.39 & 0.01 & 0.15 & 0.00 & 0.01 \\
\hline
\end{tabular}

${ }^{+}$Global index = MSCI World Index. ${ }^{*}$ L/S HF Index = Eurekahedge North America long/short Equities Index. Both hedge fund and market indices exhibit non-normal distributions using the Jarque-Bera test at the 5\% significance level.

\footnotetext{
${ }^{22}$ One of the reasons for this practice being commonly accepted is that Germany is the largest issuer of bonds in the European geographical area.

${ }^{23}$ Lhabitant (2004) defines the term benchmark as "an independent rate of return (or hurdle rate) forming an objective test of the effective implementation of an investment strategy."

${ }^{24}$ Originally hedge fund effectiveness or performance was not compared relative to a benchmark. According to Lhabitant (2004), hedge fund managers are hired for their skills and they should be allowed to venture wherever their value-creating instincts lead them, without considering benchmarks. Thus hedge fund portfolios should aim to produce positive absolute returns rather than to outperform a particular benchmark.
} 


\subsection{Methodology}

This study used a 36-month rolling (window) period to estimate the relevant statistics and ratios, beginning in January 2000. Monthly returns and risk-free rates were transformed to a geometric annualised basis using the 36month rolling period.

Annualised Sharpe ratios were calculated from monthly non-IID returns, so the estimation method accounted for serial correlation of returns. This alternative method was used as a (computational) bias that occurs when computing annual Sharpe ratios based on monthly means and standard deviations by multiplying these monthly estimates by $\sqrt{12}$. In the case of IID returns the method of computing annualised Sharpe ratios by multiplying by $\sqrt{12}$ is more suitable, but for non-IID returns, an alternative procedure that accounts for serial correlation must be used. Lo (2002) showed that ignoring serial correlation in hedge fund returns can yield annualised Sharpe ratios that are overstated by more than $65 \%$.

Table 5 presents some comparative summary statistics between the different methods of computing the annualised Sharpe ratio using the $184 \mathrm{long} /$ short equity hedge funds. Note that the summary statistics in Table 5 are based on annualised geometric returns over a 36-month rolling period with the aim of presenting a statistical comparison between the Sharpe ratio computation methods.

Table 5: Comparative Sharpe Ratio Summary Statistics (All Figures Annualised)

\begin{tabular}{|l|c|c|}
\hline & Sharpe Ratio & SC-adjusted Sharpe Ratio \\
\hline Sample size & $20056^{*}$ & 20056 \\
\hline$\mu$ & 0.38 & 0.41 \\
\hline$\sigma$ & 0.85 & 0.95 \\
\hline Median & 0.26 & 0.25 \\
\hline Min & -2.1 & -3.8 \\
\hline Max & 3.5 & 5.1 \\
\hline Skewness & 0.49 & 0.73 \\
\hline Kurtosis & 2.86 & 3.92 \\
\hline
\end{tabular}

*184 funds $\times 109$ (144-35) monthly returns.

The Bias ratio uses return data with mean $\mu$ and standard deviation $\sigma$. A closed interval $[0.0,+1.0 \sigma]$ and a half-open interval $[-1.0 \sigma, 0.0)$ need to be defined. The fund return in month $i$ is $r_{i}$ where $1 \leq i \leq n$ and $n$ is the total number of returns in the data series. The Bias ratio (BR) is then defined as:

$B R=\frac{\sum_{i=1}^{n} r_{i} \in[0.0,+1.0 \sigma]}{k+\sum_{i=1}^{n} r_{i} \in[-1.0 \sigma, 0.0)}$

The summation of the numerator is over the closed interval $[0.0,+1.0 \sigma]$, while the summation of the denominator is over the half-open interval $[-1.0 \sigma, 0.0)$. The small positive constant, $k$, is included in the formulation to prevent division by zero in instances where there are no returns reported in the interval $[-1.0 \sigma, 0.0)$. In continuous terms, Equation (3) may be stated as follows:

$B R=\frac{\int_{0}^{+\sigma} r d r}{k+\int_{-\sigma}^{0} r d r}$

The Bias ratio also has the following properties:

1. $\quad 0 \leq B R \leq n$

2. $\quad$ If $r_{i} \leq 0, \forall i$ then $B R=0$; and

3. if $r_{i}>0, r_{i}>+1 \sigma, \forall i$ then $B R=0$. 


\subsection{Application of the Bias Ratio to the Madoff Case}

A fraud measure should potentially have identified suspicious activity quite early on in the well-known Madoff Ponzi scheme, ${ }^{25}$ in what is the largest financial scandal in modern times with losses estimated at US $\$ 85 \mathrm{bn}$. Madoff Securities LLC, provided investors with modest yet steady returns and claimed to be generating these returns by trading in S\&P500 Index options. ${ }^{26}$ The Bias ratio of Fairfield Sentry Ltd., (FFS), one of the largest Madoff feeder funds, was investigated and found to have a Bias ratio of between 6 and 7, since August 2005 until its closure in 2007. For comparison, the majority of similar funds ${ }^{27}$ scored between 1 and 3 (Douady et al., 2009).

Figure 2a presents the multimodal return distribution of FFS's returns from February 1990 to December 2007. Figure $2 \mathrm{~b}$ presents the return distribution for each month rolling using a 36-month rolling (window) period. The monthly return data exhibit a monthly mean return of $0.89 \%$ while the distribution is highly positively skewed (0.81) and also leptokurtic (3.48). The skewness of the distribution is significant as it is larger than twice the standard error of skewness (SES) $(2 \times 0.333)$ (an indication of a considerable non-symmetrical distribution). The distribution also fails the Jarque-Bera test for normality with a JB-statistic of 25.7 by which the null hypothesis (normal distribution) is rejected at both the 5\% and 1\% significance levels.

(a)

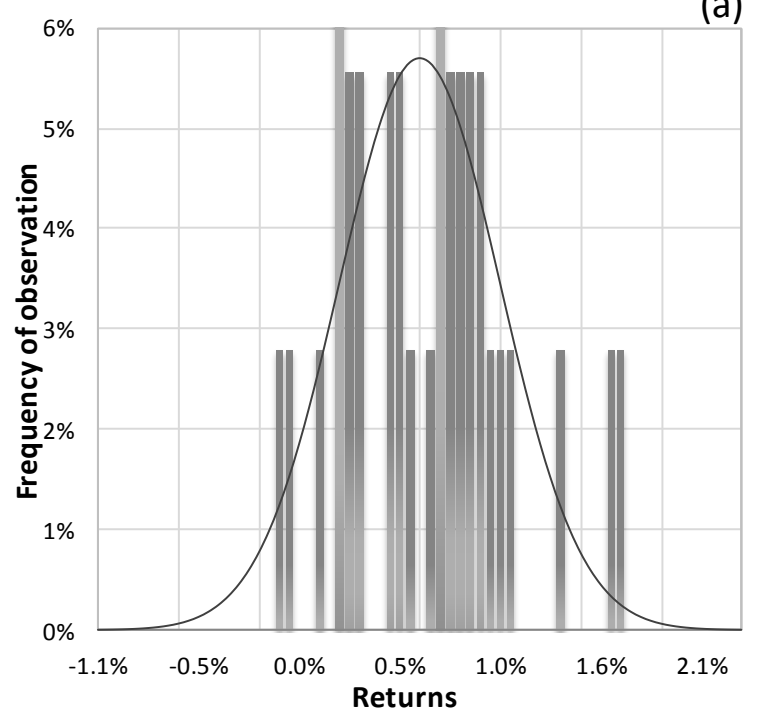

(b)

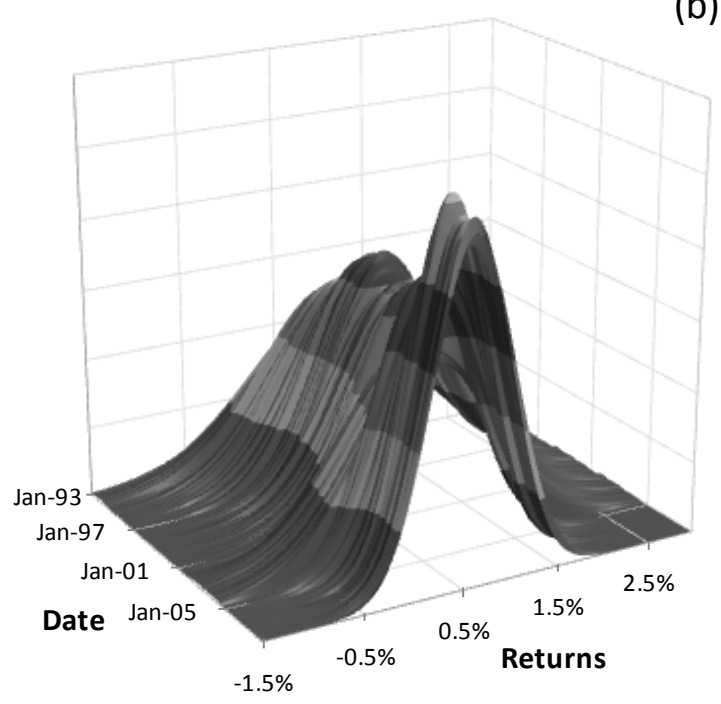

Figure 2: (a) FFS Return Distribution (February 1990 - December 2007) and (b) FFS Return Distribution for Rolling Months Using a 36-Month Rolling Period

Although FFS's return distribution is non-normal for the entire period under observation it is interesting to note that the normality of FFS's return distribution behaves in a countercyclical manner to that of the S\&P500 (Figure 3). Figure 3 is constructed using 36-months of (rolling) monthly data and the JB-statistic values below the topmost horizontal dotted-line, at 9.2, indicates a normal distribution assuming a 99\% confidence level. The bottommost horizontal dotted-line, at 6.0 represents a 95\% confidence level and again JB-statistic values below this line are indicative of a normal distribution (at this particular confidence level). As Figure 3 is based on rolling monthly returns it also shows how the goodness of fit to a normal distribution the returns distributions of both FFS and the S\&P500 changed over the time period under observation.

\footnotetext{
${ }^{25}$ Fraudulent investment operation that pay returns to investors from their own invested funds or paid by subsequent investors rather than from profit.

${ }^{26}$ Also called a "Bull-Spread." This strategy is made up of three positions: a long position on the risk asset $S_{t}$, a short position on the call option $C\left(K_{c}\right)$ and a long position on the put option $P\left(K_{p}\right)$ with $K_{p}>K_{c}$.

${ }^{27}$ Fairfield Sentry Ltd., is classified as an "equity hedge" type fund according to Hedge Fund Research (HFR) and according to Lhabitant (2004) employed an index arbitrage strategy.
} 


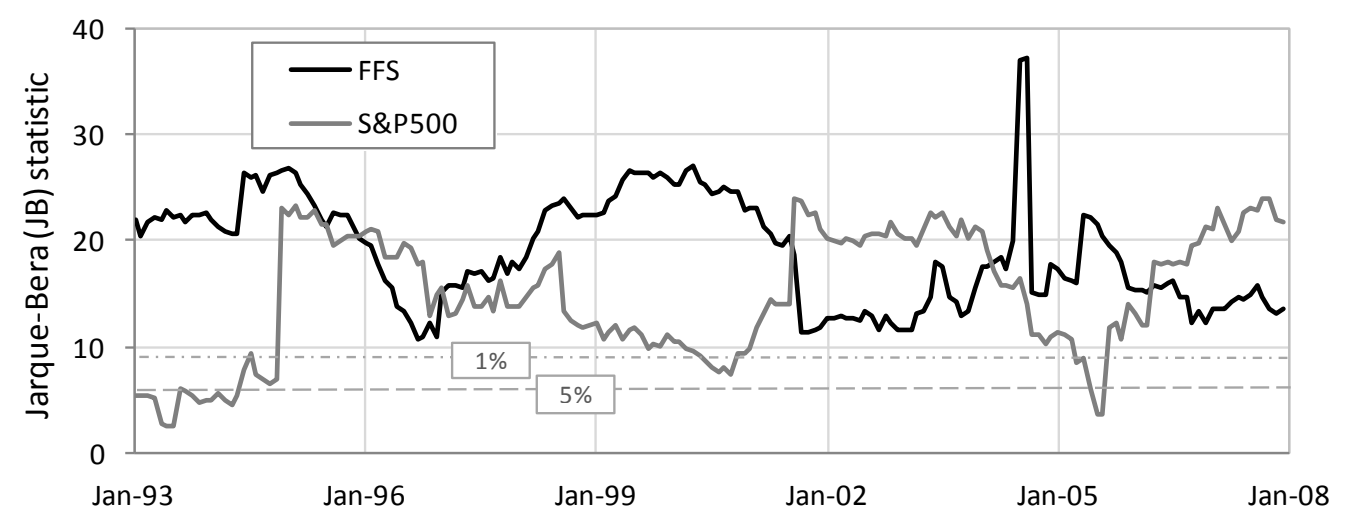

Figure 3: Rolling JB-Test Statistic as Test for Return Distribution Normality: FFS vs. S\&P500

A 36-month rolling (window) period was used to estimate the central moments of FFS's return distribution for February 1990 to December 2007, resulting in a final analysis period of February 1993 until December 2007. Figure 4a presents FFS's annualised monthly return and standard deviation, while Figure 4d presents the skewness and kurtosis of FFS.
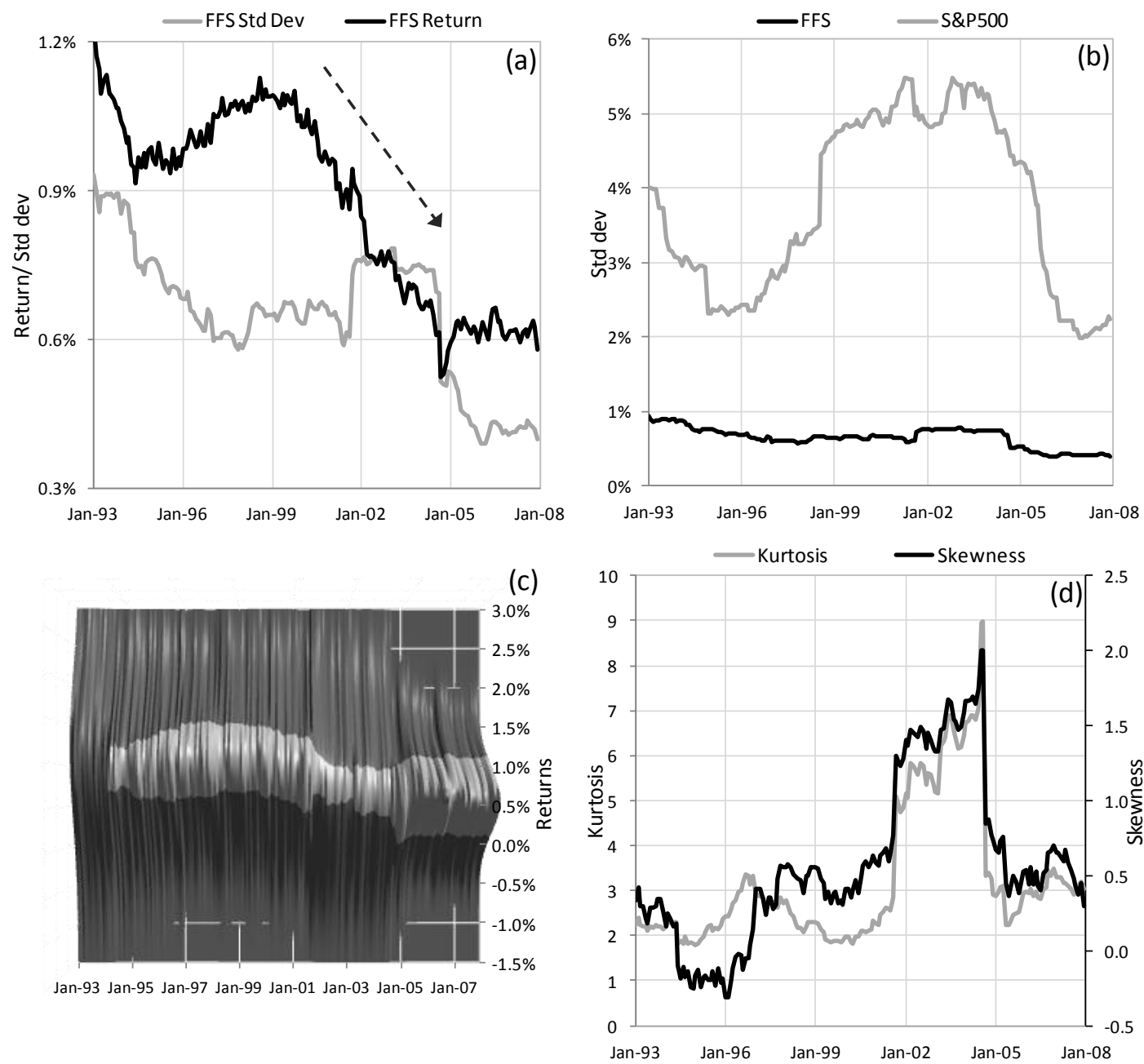

Figure 4: (a) FFS Annualised Monthly Return and Standard Deviation, (b) Volatility Comparison: FFS vs. S\&P500, (c)

Plan View of FFS (annualised) Return Distribution Through Time and (d) FFS Skewness and Kurtosis 
Monthly returns are relatively high and consistently so (Figures 4a and 4c), while volatility is relatively low for such high monthly returns (Figure 4a), and the same compared to the S\&P500's volatility (Figure 4b). Note that in Figure $4 \mathrm{c}$ the lightest shading area represents FFS's average monthly returns. The combination of consistently high returns and low volatility leads to strangely high Sharpe ratios (Figure 5b), which are also dramatically higher than those of the S\&P500. Only 10 out of the 215 months of data available for the FFS feeder fund exhibit negative performance. The monthly returns of FFS are also not correlated with those of the S\&P500: the correlation coefficient $=0.014$.

Figure $4 \mathrm{~d}$ draws attention to the high skewness and kurtosis that the return distribution exhibits in comparison to previous values. The negative kurtosis (fat tails) during the earlier part of the time series along with the extremely high kurtosis towards the latter end of the series signal potentially suspicious behaviour. The dramatic increase and decrease of both skewness and kurtosis in September 2001 and September 2004, respectively, are also of interest.

Figure 5a shows the Bias ratios and Figure $5 \mathrm{~b}$ the (serial correlation-adjusted) Sharpe ratios for FFS and the S\&P500 (as comparison) using a 36-month rolling period.
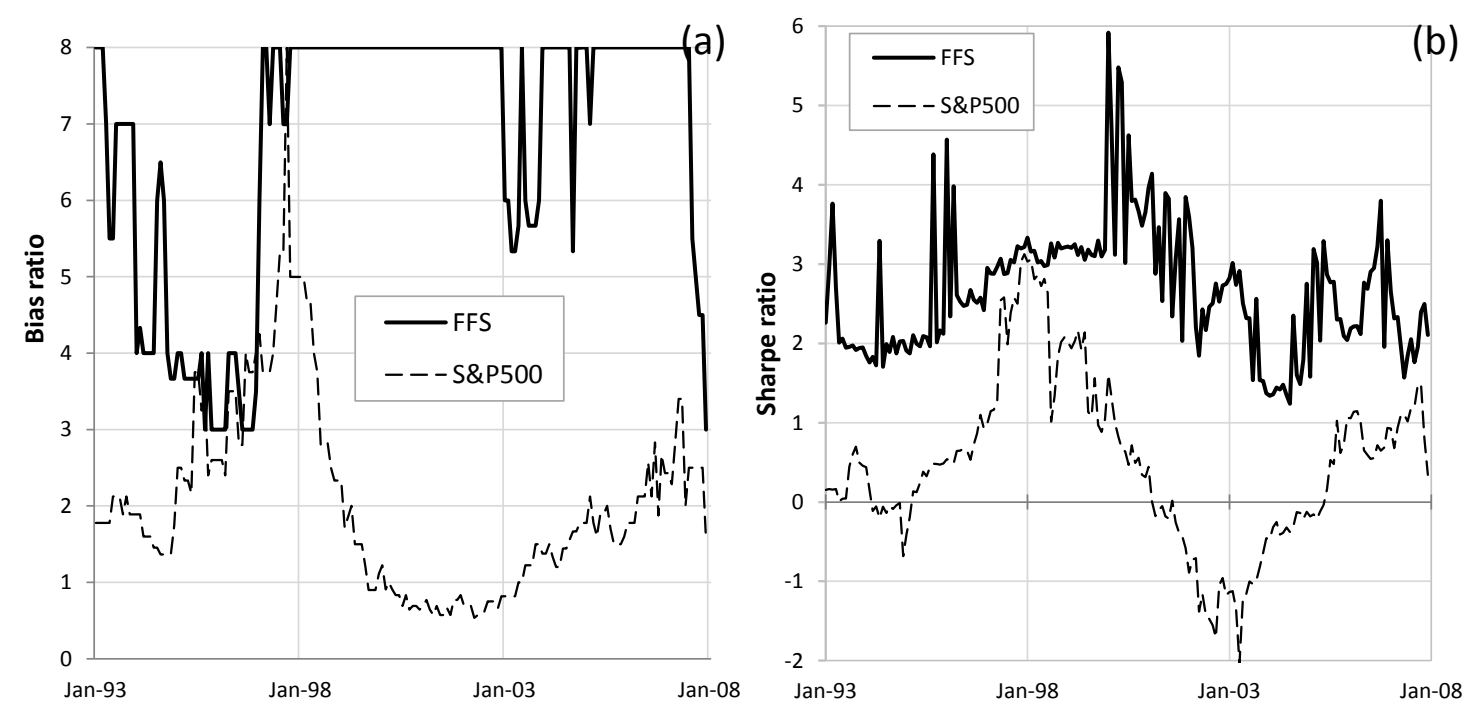

Figure 5: (a) Bias Ratio: FFS vs. S\&P500 and (b) Sharpe Ratio: FFS vs. S\&P500

The Bias ratio of FFS ranges from 3 to 8 , while the bulk of other equity hedge funds in the HFR database scored a Bias ratio mostly in the range of 1 to 3. As reference, Beacon Hill's Safe Harbour (a MBS fund) had a Bias ratio of 7 until fraud was discovered in 2002. As the Bias ratio analyses fund returns to measure how far they are from an unbiased distribution, the Bias ratio of an equity index or fund where valuation is based on market prices (i.e., trading liquid securities) would have a Bias ratio typically close to 1 . In contract, a fund that smoothes returns will have a much higher Bias ratio. Alternative opinions include that a fund's Bias ratio should be compared to other funds of a similar strategy. Although the Bias ratio goes to infinity, it is capped at 8 in Figure 5a, but this does not have any material impact as a Bias ratio significantly larger than 1 is suspicious and even more so if the Bias ratio is higher than that of comparative funds. Figure $5 \mathrm{~b}$ also shows how significantly FFS outperforms the market on a riskadjusted basis (as measured by the Sharpe ratio). It should be remembered that extremely high Sharpe ratios are also cause for suspicion, while suspicion should escalate considering extremely high Sharpe ratios compared to similar funds. Figure 5a and Figure 5b clearly show that FFS's Bias ratio and Sharpe ratio, respectively, are (consistently) abnormally high (over a long time period). The level of both these measures indicate clear warnings.

Also of significance is that FFS's serial correlation coefficients are low $\left(\rho_{1}=-0.19, \rho_{2}=0.20, \rho_{3}=\right.$ 0.10 ) while the LB-Q statistic's $p=0.01$. Although a lower $p$-value is stronger evidence against the null hypothesis of no serial correlation, the fact that the first-order autocorrelation coefficient is $\leq 0.30$ also indicates liquidity. This along with the near zero levels of the autocorrelation coefficients indicate that FFS traded liquid instruments and 
thus it can be assumed that any relevant irregularities are not due to illiquidity exposures: smoothing practices remain as the only explanation.

By studying the moments of FFS's returns distribution to those of the relevant market (S\&P500), the following out of the ordinary characteristics were identified. These returns distribution characteristics can consequently be thought of as potential warning signals of fraud, as they were discovered through meticulously studying the Madoff case, a scenario that has been formally classified as fraudulent and that included the practice of returns smoothing. These potential fraud warning signals are presented consecutively for ease of interpretation.

The first two warning signals, (Figure 6a and b), are:

1. a highly infrequent negative mean return accompanied by minimal variation of the mean return; and

2. a non-volatile rolling standard deviations of returns being significantly lower than those of the relevant market (Figure 6b). The returns distribution's third and fourth moments deliver the third and fourth potential warning signals (Figure $6 \mathrm{c}$ and 6 respectively). The skewness of FFS's returns distribution is much less volatile than that of the relevant market (S\&P500) and almost never negative (Figure 6c). The fourth fraud warning signal shows the returns distribution's kurtosis moving in the opposite direction to the market (Figure 6d). This anti-correlation, (Figure 6d), is evidenced by FFS's kurtosis increasing when the S\&P500's kurtosis is decreasing and vice versa. These identified return characteristics emphasise that return characteristics that are dissimilar to those of the relevant market should be treated as warning signals of potential fraudulent activity.
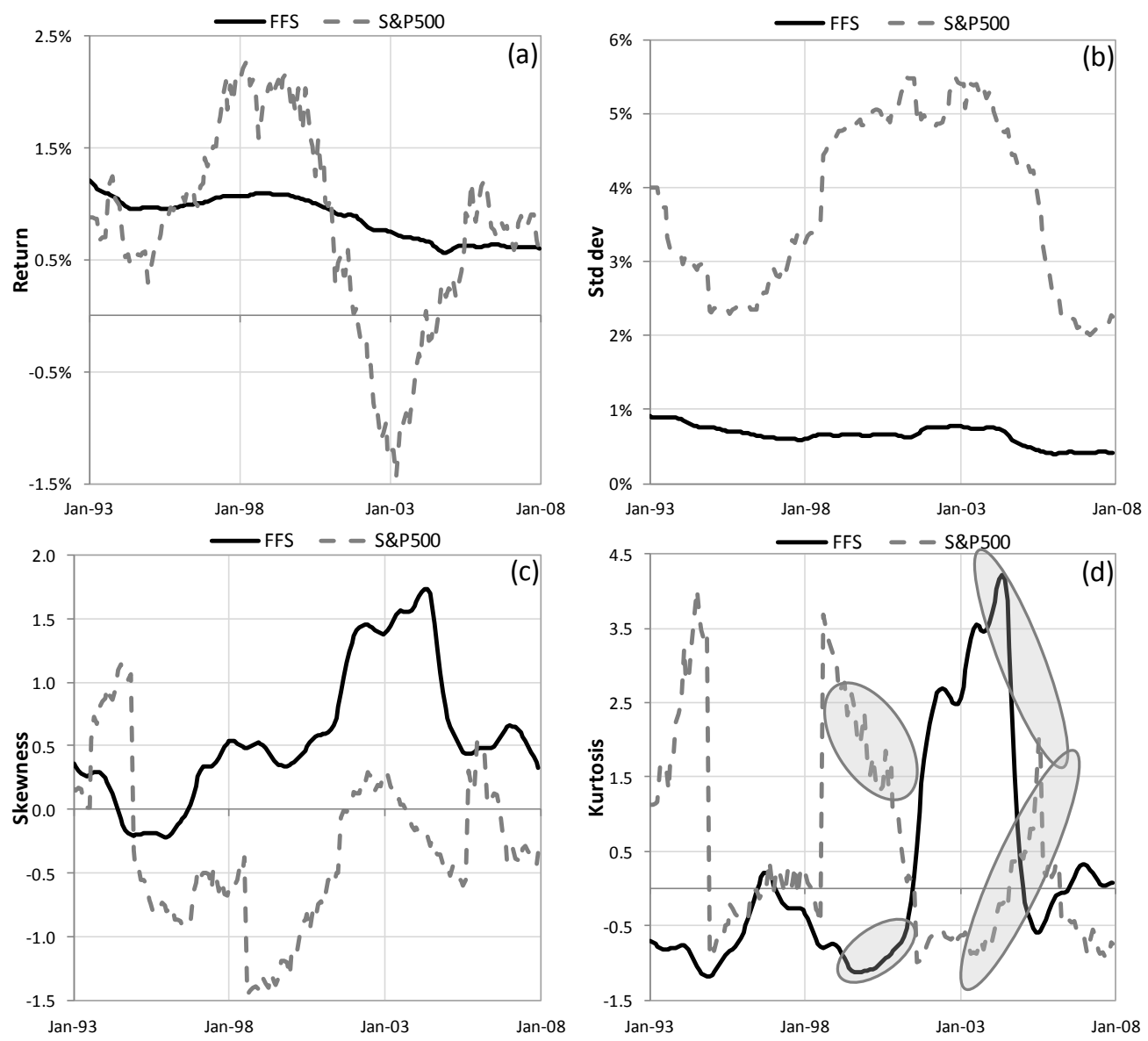

Figure 6: (a) Mean Return: FFS vs. S\&P500, (b) Standard Deviation: FFS vs. S\&P500 Returns,

(c) Skewness: FFS vs. S\&P500 and (d) Kurtosis: FFS vs. S\&P500

* Figures are based on (rolling) monthly returns using 36-months. 
The Bias ratio should also be consulted and scrutinised. The Bias ratio of FFS behaves in the opposite fashion to that of the market (S\&P500 - Figure 5a). This is highlighted by the observation that FFS's Bias ratio is highest when the Bias ratio of the S\&P500 is at its lowest and also that FFS's Bias ratio is decreasing when that of the S\&P500 is increasing. As mentioned prior, out of the ordinary high Sharpe ratios can also be cause for suspicion and that suspicion should rise in the event of abnormally high Sharpe ratios compared to similar funds. Figure 5b shows that FFS's Sharpe ratio is always higher than that of the S\&P500s and FFS's Sharpe ratio is never negative. Also worth noting is that FFS's Sharpe ratio is low when the S\&P500's Sharpe ratio is high, compared to the general spread between the two Sharpe ratio series over the time period.

The reverse behaviour of FFS's Jarque-Bera (JB) statistic, as a test for normality of the return distribution, compared to that of the S\&P500 might arguably also be considered as a potential signal of suspicious or fraudulent activity (Figure 3).

\section{ANALYSIS AND RESULTS}

\subsection{Ill-Suitedness of the Sharpe Ratio}

Table 6 presents higher moment estimates for the hedge fund data to point out how ill-suited the Sharpe ratio is for (these) hedge fund return data, or how inaccurate (these) hedge fund data are for use with the Sharpe ratio. In terms of skewness, Table 6 indicates that funds from all the geographical mandated areas, except global mandated funds, exhibit excess skewness $(>0.50)$, mostly positive. Asia mandated funds exhibit negative skewness. Table 6 also indicates that the funds from all geographical areas are severely leptokurtic and significantly so according to the standard error of kurtosis (SEK).

Table 6: Hedge Fund Higher Moment Estimates

\begin{tabular}{|l|c|c|c|c|c|}
\hline & All Funds & North America & Europe & Asia & Global \\
\hline Skewness & 0.75 & 1.14 & 0.49 & -0.15 & 0.05 \\
\hline S.E. Skewness (SES) & 0.18 & 0.27 & 0.40 & 0.63 & 0.36 \\
\hline Kurtosis & 18.40 & 22.29 & 10.01 & 4.87 & 9.58 \\
\hline S.E. Kurtosis (SEK) & 0.36 & 0.53 & 0.79 & 1.26 & 1.44 \\
\hline
\end{tabular}

The Jarque-Bera (JB) test indicates that only 29 of out the 184 funds (15.8\%) exhibit normal distributions at the 5\% significance level, while the remaining 155 funds (84.3\%) have non-normal return distributions. Figure 7 depicts the state of normality of the return distributions for both the funds (Figure $7 \mathrm{~b}$ ) and the relevant market indices (Figure 7a) through time. Figure $7 \mathrm{a}$ and $7 \mathrm{~b}$ are constructed using 36-months of rolling monthly data while the two horizontal dotted-lines represent the thresholds for distribution normality at the $1 \%$ and $5 \%$ significance levels respectively. Jarque-Bera (JB) test statistical values below these thresholds are indicative of normal distributions at the relevant level of significance.
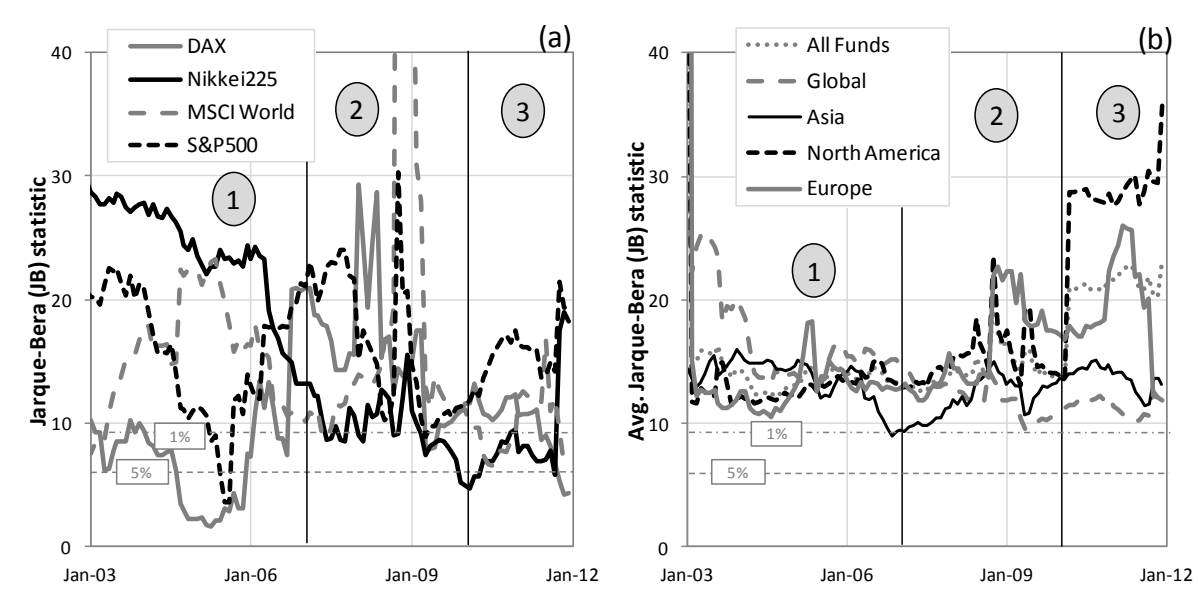

Figure 7: (a) Rolling JB-Test Statistic of Relevant Market Indices and (b) Average Rolling JB-Test Statistic for All Funds and also for Hedge Funds per Geographical Mandate, Over Time 
Figure 7 is also divided into three phases or periods by the vertical lines. Each of these three periods represents a specific period relating to the 2007 financial crisis: (1) pre-crisis, (2) during the crisis, and (3) postcrisis (i.e., after the height of the crisis). Figure 7a indicates that some of the market indices pass the (rolling) goodness of fit test for normal return distributions at either or both the $1 \%$ and $5 \%$ significance levels (horizontal dotted-lines) using the JB-test statistic. The instances where a few market indices do pass as normal distributions, however, only occur in limited cases and for short and limited time spans. The (rolling) average JB-test statistic, as per Figure $7 \mathrm{~b}$, depicts that funds from all regional mandates are non-normal for the entire time period under investigation with the exception of the Asian mandated funds that show return distribution normality but only for November 2006 - this is fairly insignificant considering the Asian mandated funds are, on average, only considered normal for 1 out of 109 rolling months. Also noticeable is the rapid and elaborate increase (further) away from normality during 2008, and also high non-normality for North American and European mandated funds. By further comparing the average normality of funds for a specific regional mandate to its relevant market index it is apparent that trends and trend changes and also the magnitude of change do, for the most part, not coincide while at certain times rather odd comparative behaviour is witnessed.

Figure 8a presents the skewness and Figure $8 \mathrm{~b}$ the kurtosis of the funds grouped per mandated geographic region by means of a candlestick like chart indicating the mean, maximum and minimum of these distribution moments.
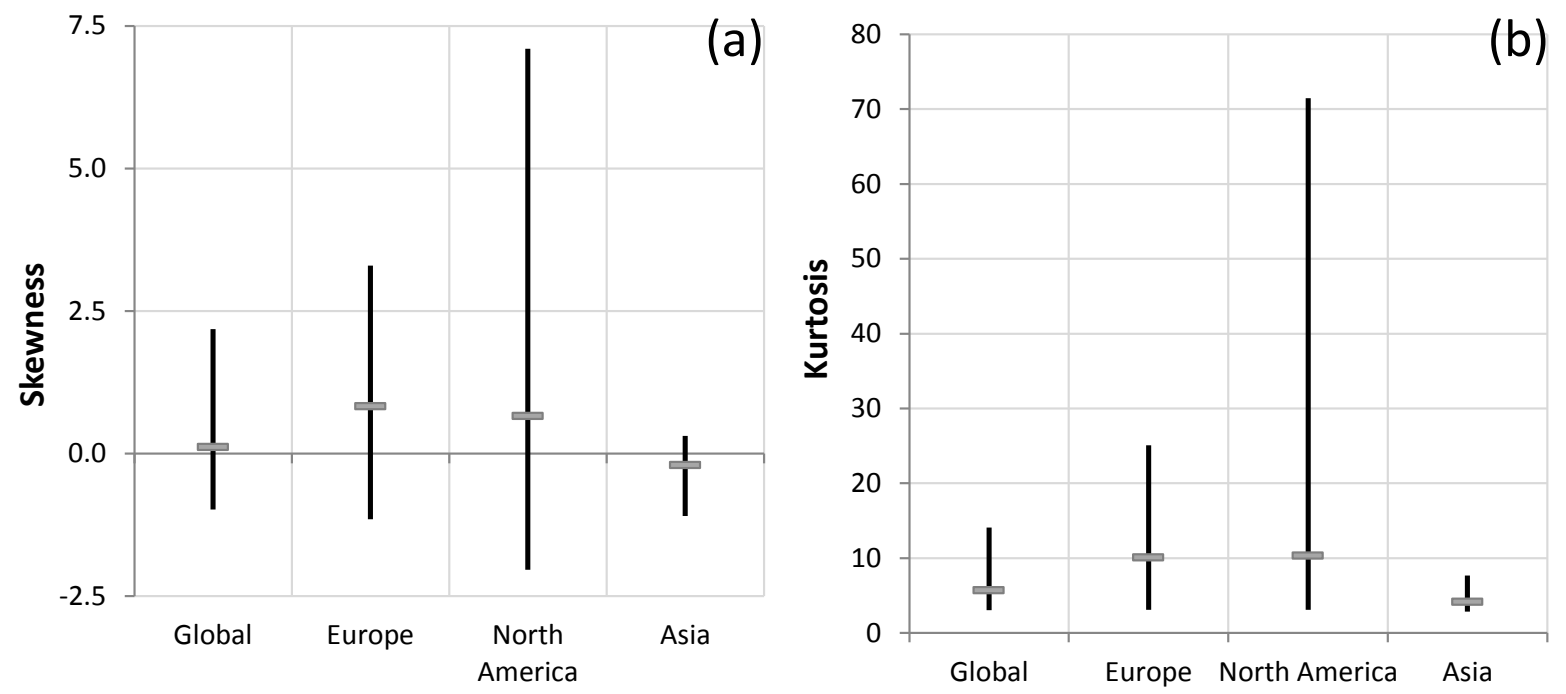

Figure 8: (a) Skewness of Individual Funds per Region and (b) Kurtosis of Individual Funds per Region

Table 6 in conjunction with Figures 7 and 8 confirm that most of the return distributions of these hedge funds are not ideally suited for Sharpe ratio application. The $15.8 \%$ of funds that show evidence of normal distributions through the JB-test might be possible exceptions. This will, however, leave investors requiring to test each fund for normality before applying the Sharpe ratio, which is not ideal.

To further demonstrate how ill-suited these funds' distributions are to the Sharpe ratio, not only at a pointin-time but also through time, the rolling skewness and kurtosis are presented in Figure 9. Figure 9 presents the average skewness (Figure 9a) and kurtosis (Figure 9b) by using the 36-month rolling period. Figure 9 is again divided into three phases or periods by means of vertical lines with each period representing a specific period relating to the 2007 financial crisis consistent with those declared earlier (see Figure 7). 

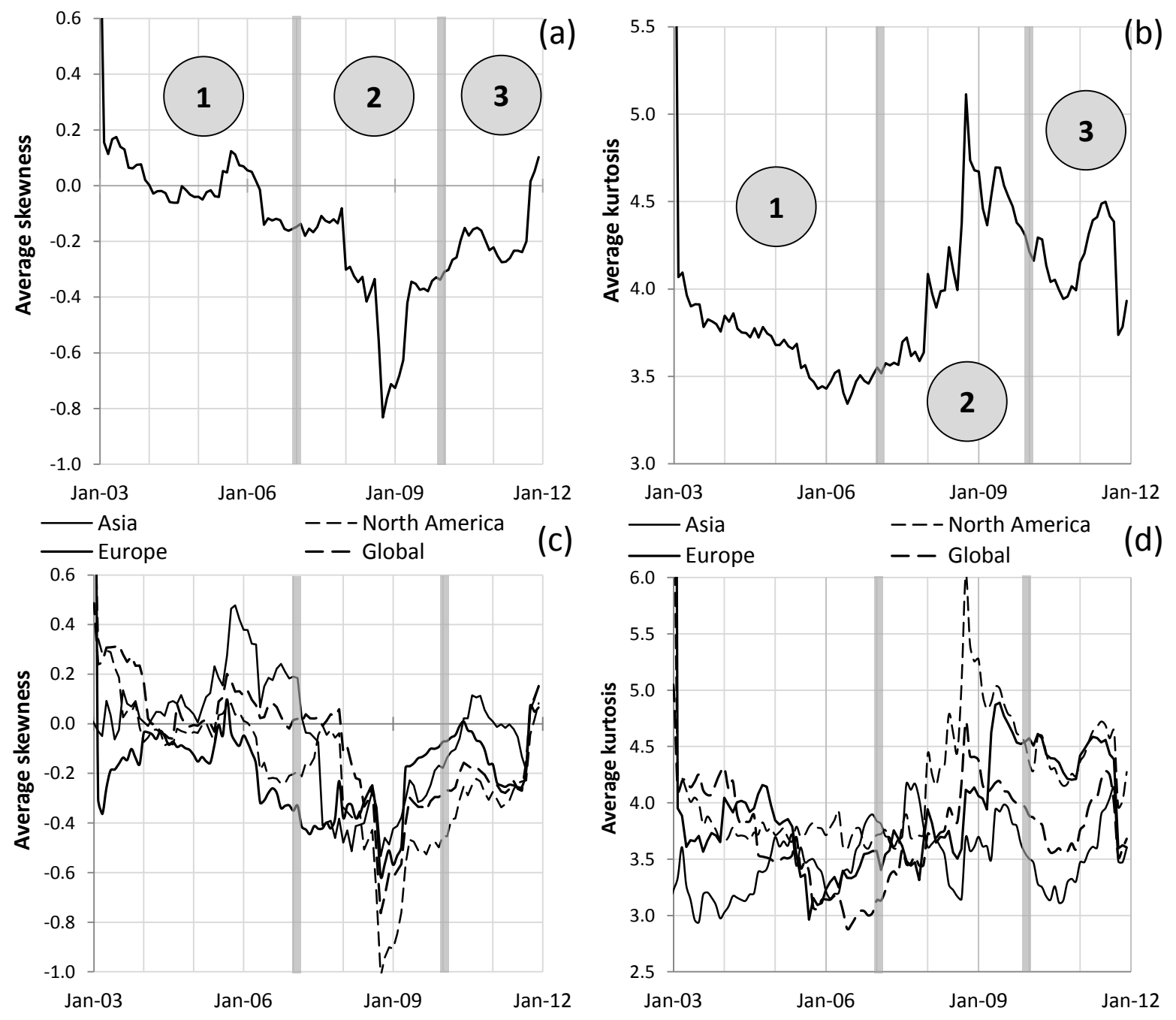

Figure 9: Average Values, Through Time, for (a) Skewness - All Funds, (b) Kurtosis - All Funds,

(c) Skewness - per Region and (d) Kurtosis - per Region

The average skewness turned considerably negative during the financial crisis, while average kurtosis, which was at high levels prior, reached extreme levels. The data presented in Table 6 along with Figures 7, 8, and 9, strengthen the case that the Sharpe ratio is not adequately compatible with the distributions of these hedge funds.

The Bias and Sharpe ratios were also analysed using the rolling period analysis method. For this, the results focusing on funds mandated for the North America region are presented in Figure 10. 

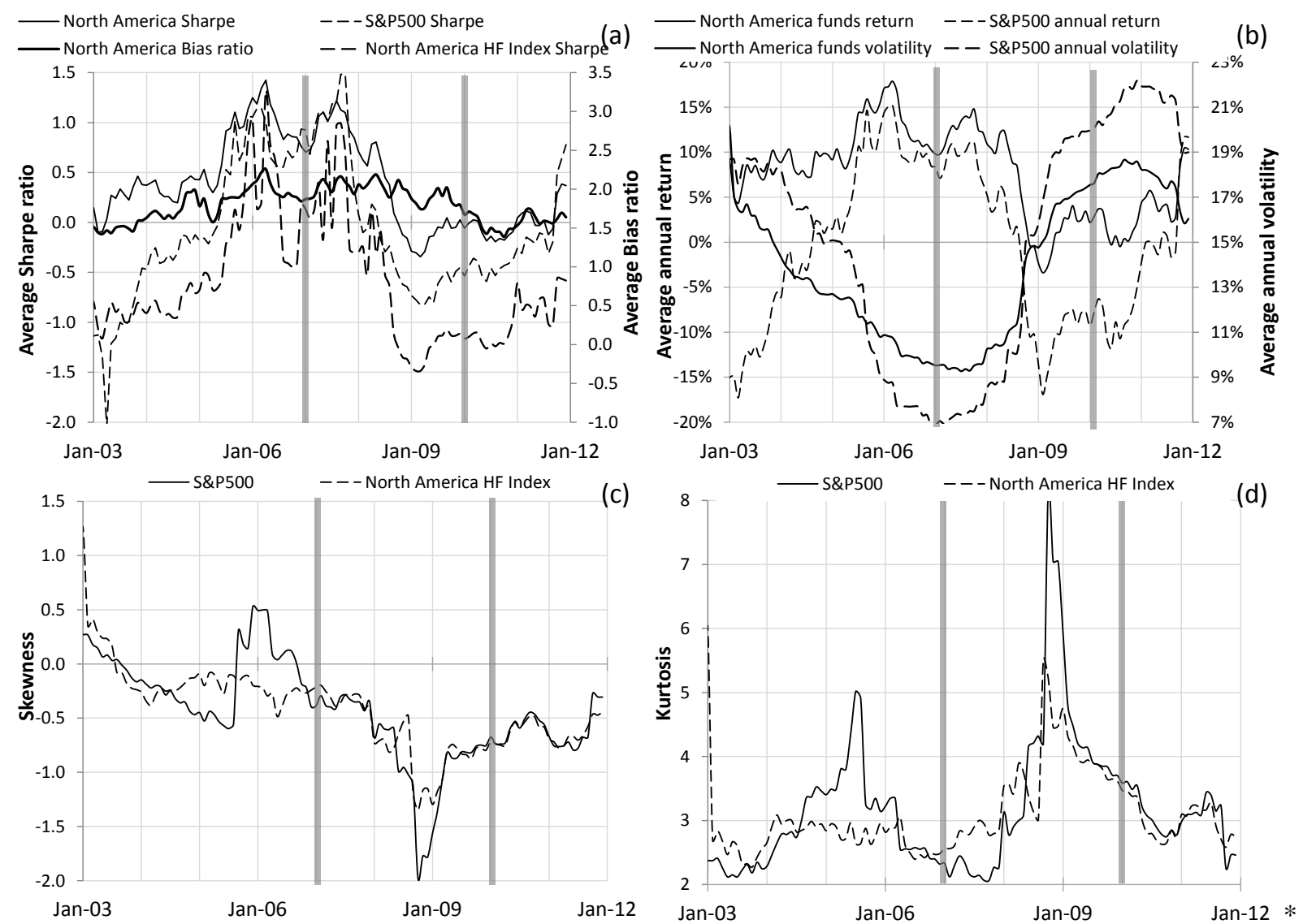

Figure 10: (a) North America Funds Average Sharpe Ratio vs. Average Bias Ratio, (b) North America funds Average Annual Return vs. Average Annual Volatility, (c) North America Funds' Benchmarks* Skewness and (d) North America Funds' Benchmarks Kurtosis

Hedge fund index in Figure 10: Eurekahedge North America Long/Short Equities Hedge Fund Index.

The higher moments of the hedge fund benchmarks, as depicted in panels (c) and (d) of Figure 10, also indicate the inappropriateness (of these return distributions) for the use of the Sharpe ratio. Panels (c) and (d) also indicate the altered behaviour for these higher moments of the return distribution around the time period of the recent financial crisis. The financial crisis also impacted the returns of these funds along with their volatility (Figure $10 \mathrm{~b})$. Figure 10b shows the decline in returns and the increase in volatility for both these mandated funds and the S\&P500 during the crisis time period. Figure 10a presents the average Bias and average Sharpe ratios specifically for the funds with North America mandates (along with the Sharpe ratios for relevant benchmarks). From Figure 10a it is evident that the average Bias ratio for the funds with North America mandates are relatively higher around the financial crisis. The average Sharpe ratios for these mandated funds are also consistently higher than those of the benchmarks, except for a period of extreme volatility (late 2005 until the end of 2007) in the relevant hedge fund index (see Figure 10a).

\subsection{Identifying Suspicious Funds using Madoff Identified Warning Signals}

Using the identified warning signals from the Madoff case (Section 3.5) this section presents two funds ${ }^{28}$ from the funds sample that exhibit extraordinary characteristics and which can be considered as potential warning signals of fraudulent or suspicious behaviour. The first of the identified funds (fund \#7) has a European regional mandate while the second has a global mandate (fund \#83). The methodology and 36-month rolling analysis as

${ }^{28}$ A number of funds (15 in total) were identified using the warning signals from the Madoff case. Two characteristic funds are presented in this section to show how these warning signals could be used to identify potentially fraudulent funds. 
discussed in Section 3.4 and as used in the Madoff application case (Section 3.5) are again used. The identified warning signals are presented graphically with the relevant market indices as indicated in Section 3.3.

Figures 11a and $11 \mathrm{~b}$ show that neither of the funds have negative annualised mean returns while both funds also, for the most part, exhibit return levels that are never negative and are also above that of their relevant market indices. Figure $11 \mathrm{~b}$, in particular, highlights the low levels of mean variation for the global fund. According to Figures $11 \mathrm{c}$ and $11 \mathrm{~d}$, fund $\# 7$ and fund \#83 display annual volatilities that are both significantly lower and less variable than that of their respective market indices.
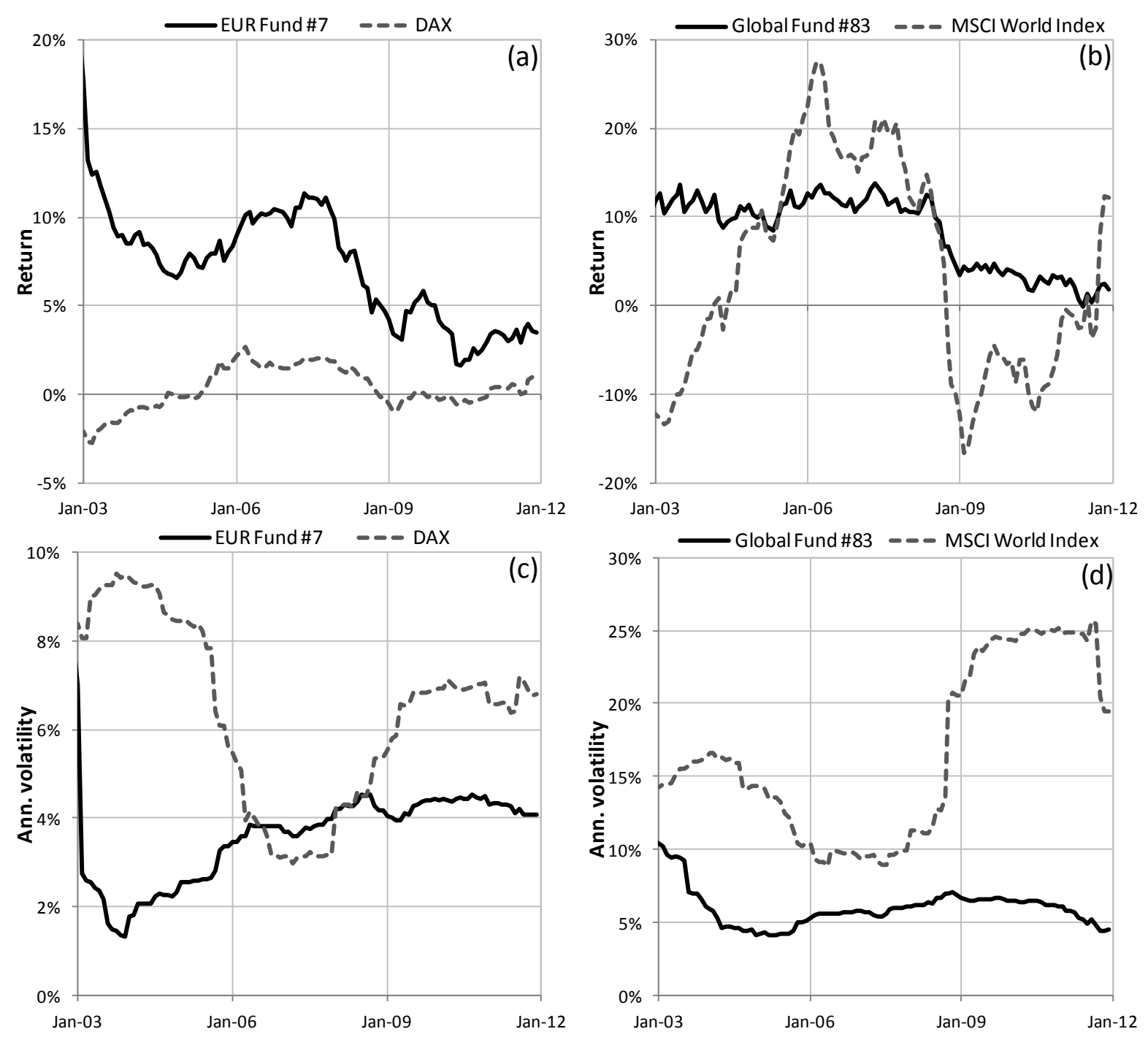

Figure 11: (a) Annualised Return: EUR Fund \#7 vs. DAX, (b) Annualised Return: Global Fund \#83 vs. MSCI World, (c) Annualised Volatility: EUR Fund \#7 vs. DAX and (d) Annualised Volatility: Global Fund \#83 vs. MSCI World

Figures 12a and $12 \mathrm{~b}$ show that the skewness of both funds is much less volatile than their respective market indices, while also being positive for longer periods of time than the market indices. Figures $12 \mathrm{c}$ and $\mathrm{d}$ illustrate the mostly anti-correlated nature of both funds' kurtosis in relation to their respective market benchmarks. 

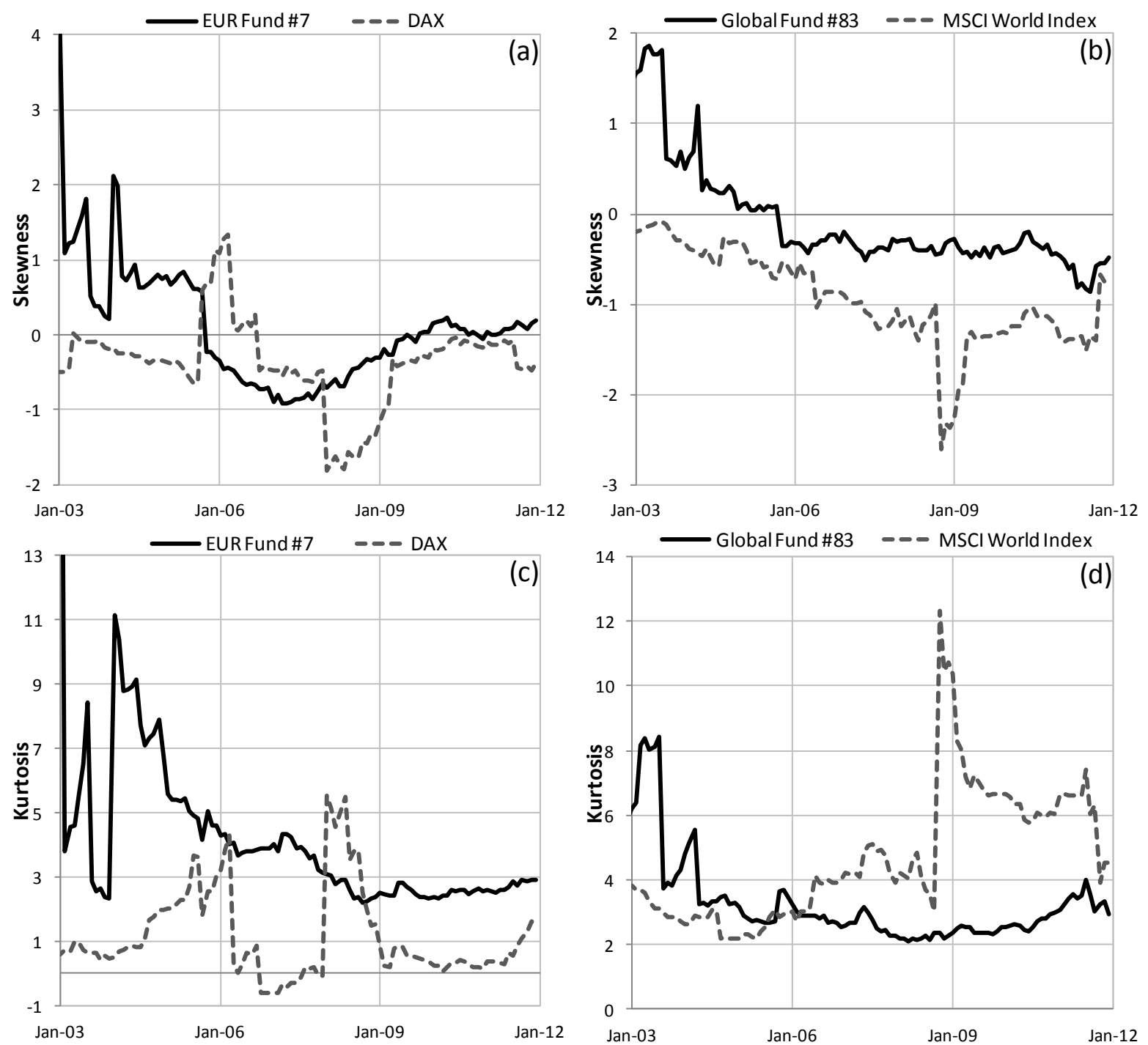

Figure 12: (a) Skewness: EUR Fund \#7 vs. DAX, (b) Skewness: Global Fund \#83 vs. MSCI World, (c) Kurtosis: EUR Fund \#7 vs. DAX and (d) Kurtosis: Global Fund \#83 vs. MSCI World

The Bias ratios of both identified funds show similar characteristics to FFS's Bias ratio (see Section 3.5) in that the ratios exhibit an opposite, and to some extent, anti-correlated relationship to that of the relevant market (Figure 13). The abnormally high Bias ratios of both funds are visible in Figures 13a and 13b and these ratios are especially abnormal for the period at the initial stages of the observation period - during this period the funds' Bias ratios are significantly larger than those of the respective markets. Figures $13 \mathrm{c}$ and $13 \mathrm{~d}$ convey that both funds mostly deliver positive Sharpe ratios, and also positive Sharpe ratios of a considerable level on a regular frequency. The funds also predominantly produce larger Sharpe ratios than those of their respective market indices. Moreover, the funds' and market's Sharpe ratios do appear to follow each other's trend, although there are instances where this trend following phenomenon breaks down - leading to occurrences where a low market Sharpe ratio is simultaneous to a high fund Sharpe ratio. The instances with abnormally high fund Bias ratios also coincide with high fund Sharpe ratios relative to those of the respective markets. This is relevant as abnormally high Sharpe ratios are also cause for potential concern and or suspicion. 

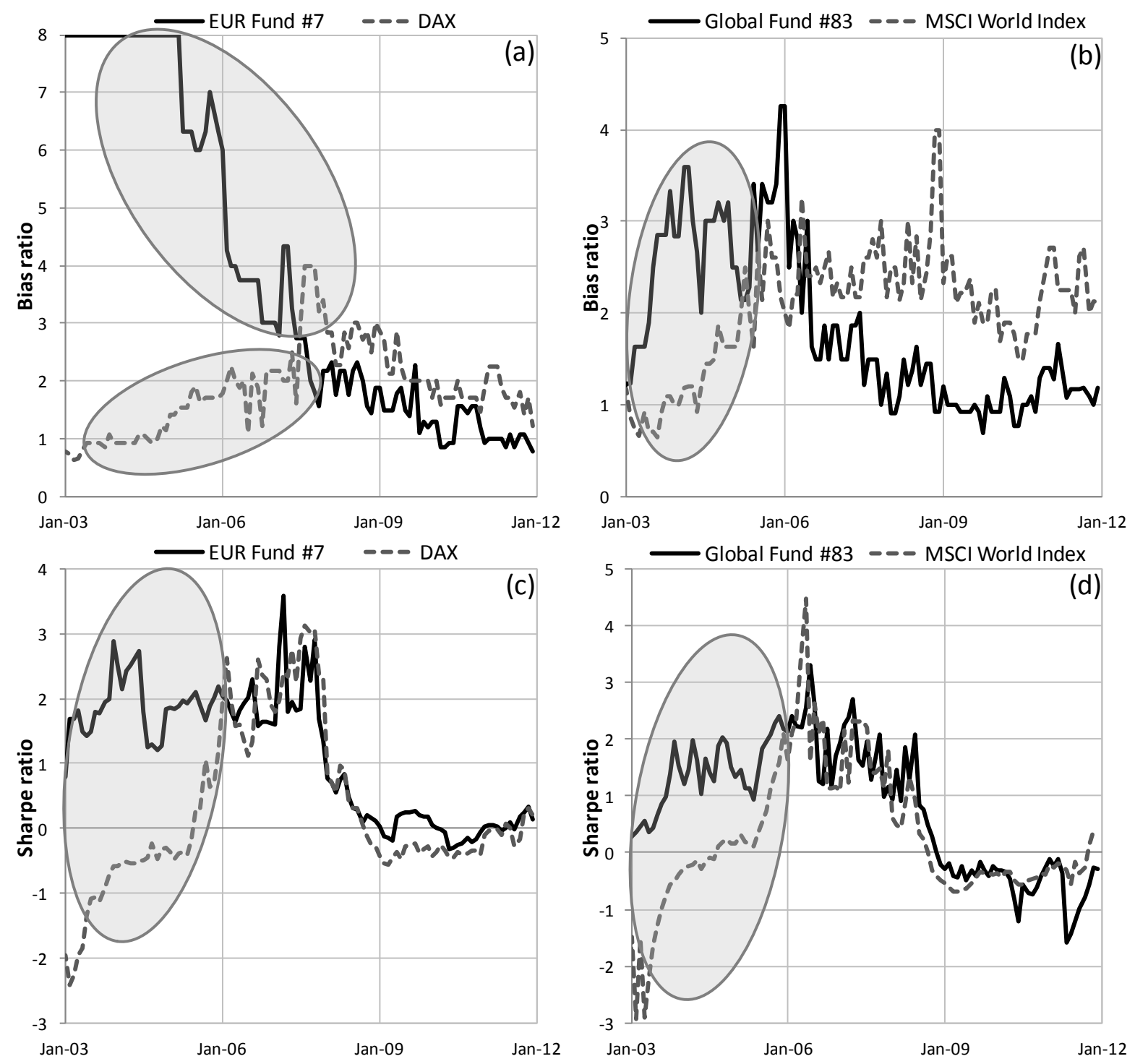

Figure 13: (a) Bias Ratio: EUR Fund \#7 vs. DAX, (b) Bias Ratio: Global Fund \#83 vs. MSCI World, (c) Sharpe Ratio: EUR Fund \#7 vs. DAX and (d) Sharpe Ratio: Global Fund \#83 vs. MSCI World

The Madoff case also exhibited a potential signal of suspicious or fraudulent behaviour through the predominantly reverse behaviour of its Jarque-Bera (JB) statistic, as a return distribution normality test, relative to that of the market. Figure 14a and 14b present the rolling Jarque-Bera (JB) statistic for fund \#7 and fund \#83 respectively and also relative to the $\mathrm{JB}$-statistics of their relevant market benchmarks. 

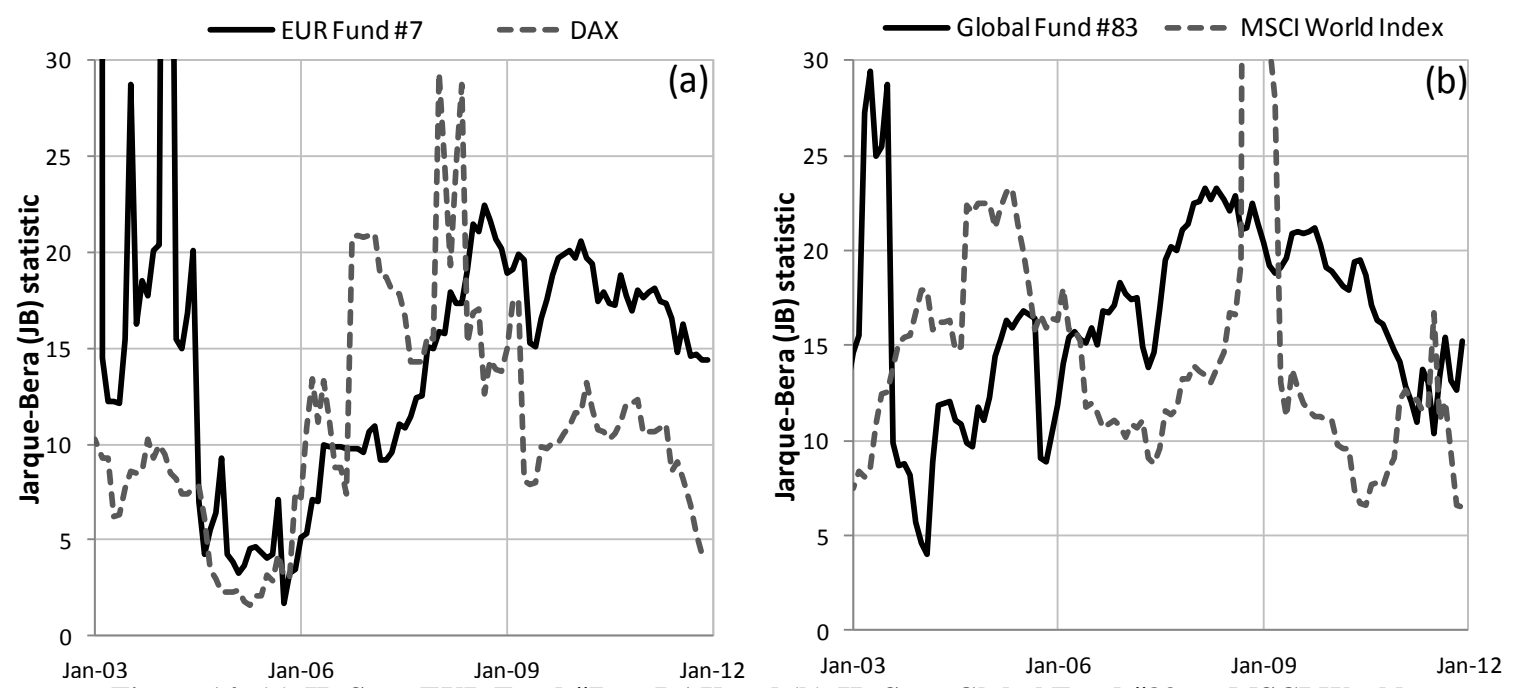

Figure 14: (a) JB-Stat: EUR Fund \#7 vs. DAX and (b) JB-Stat: Global Fund \#83 vs. MSCI World

Like the Madoff case a largely reverse or opposite behaviour in terms of return distribution normality, through the JB-statistic, relative to that of the relevant market benchmark can be observed for both funds (Figure 14a and Figure 14b).

\subsection{Selective Statistics over Different Economic Conditions}

Selective summary performance statistics focusing on returns, Sharpe and Bias ratios for both the hedge funds and the relevant market benchmarks to these funds are presented in this section. As the statistics are partitioned into three phases it highlights the altering characteristics of the funds and their market benchmarks throughout different economic periods. The three phases represent the periods prior, during, and post the 2007 financial crisis. December 2002 until December 2006 constitutes phase 1, January 2007 until December 2009 phase 2, and January 2010 until December 2011 phase 3. The rolling annual calculation methodology based on 36-months, as discussed in Section 3.4, is employed in this section. Also, although the Bias ratio goes to infinity it is capped at 8 in this section, but this does not have any material impact as a Bias ratio significantly larger than 1 is suspicious and even more so if the Bias ratio is higher than that of comparative funds.

The changing characteristics during the three economic phases are presented in Figure 15 through the average Sharpe ratio and also the average annual return and standard deviation for all funds in this study. The summary statistics for all funds per phase is conveyed in Table 7.

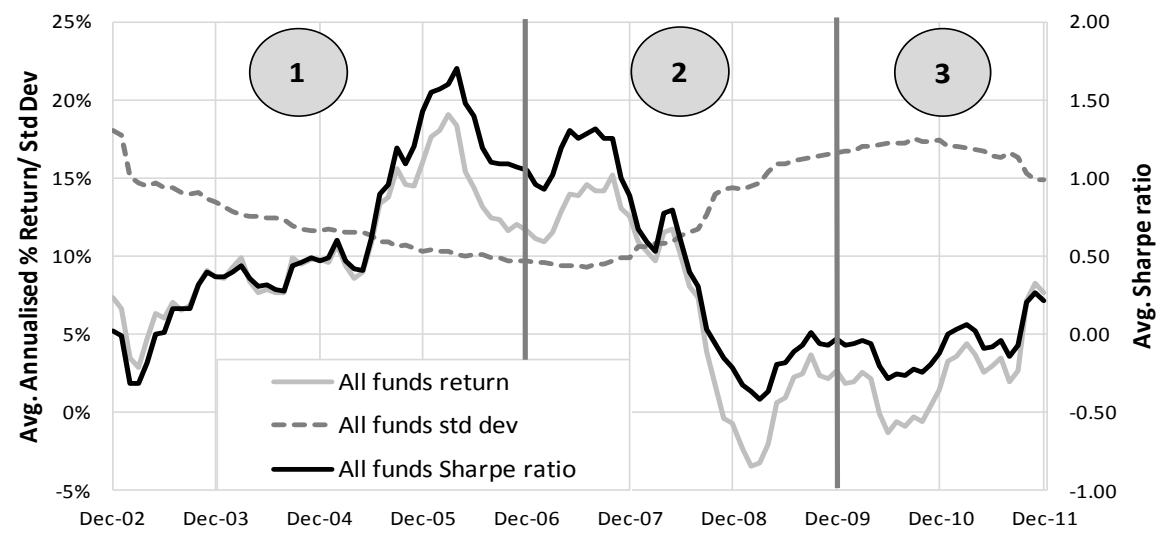

Figure 15: Average Annual Return and Standard Deviation and Also Sharpe Ratio for All Hedge Funds 
Figure 15 shows the impact of the 2007 financial crisis as a decrease in the average Sharpe ratio of all funds in phase 2 suggests. This figure further draws attention to the decrease in the average returns across all funds in conjunction with a nearly simultaneous increase in volatility during the crisis period. Of further significance is that mostly during phase 2, the period during the 2007 financial crisis, the average Sharpe ratio of all funds reduces to below zero which implies that a risk-less asset would have performed better on average during this time compared the analysed funds sample. The visual results in Figure 15 are reverberated in the summary statistics as per Table 7, which indicates similar declining average returns and Sharpe ratios for all funds from phase 1 through to phase 3. Both the average and median Bias ratio increase from phase 1 to phase 2 where after decreasing in phase 3 to its lowest level throughout all phases - indicating that suspicious fund behaviour peaked in the period during the crisis. Interestingly the standard deviation of returns and the Sharpe ratio reduce over time indicating that the performance spectrum between funds diminishes, on average. Similarly the Bias ratio's standard deviation also decreases moving through phase 1 to phase 3 .

Table 7: Summary Statistics for All Hedge Funds per Phase

\begin{tabular}{|c|c|c|c|c|c|c|c|c|c|}
\hline & Phase 1 & Phase 2 & Phase 3 & Phase 1 & Phase 2 & Phase 3 & Phase 1 & Phase 2 & Phase 3 \\
\hline & \multicolumn{3}{|c|}{ Return Statistics } & \multicolumn{3}{|c|}{ Bias Ratio Statistics ${ }^{*}$} & \multicolumn{3}{|c|}{ Sharpe Ratio Statistics } \\
\hline$n$ & 9016 & 6624 & 4416 & 9016 & 6624 & 4416 & 9016 & 6624 & 4416 \\
\hline$\mu$ & $10.41 \%$ & $6.86 \%$ & $2.39 \%$ & 1.78 & 1.94 & 1.45 & 0.63 & 0.43 & -0.07 \\
\hline$\sigma$ & $10.93 \%$ & $10.20 \%$ & $8.38 \%$ & 1.11 & 1.05 & 0.62 & 1.03 & 0.92 & 0.54 \\
\hline Median & $9.59 \%$ & $7.33 \%$ & $2.21 \%$ & 1.50 & 1.67 & 1.36 & 0.54 & 0.31 & -0.11 \\
\hline Min & $-44.96 \%$ & $-48.39 \%$ & $-36.57 \%$ & 0.29 & 0.26 & 0.25 & -3.79 & -1.95 & -2.30 \\
\hline Max & $59.50 \%$ & $42.39 \%$ & $74.39 \%$ & 8.00 & 8.00 & 7.00 & 5.07 & 4.39 & 4.12 \\
\hline
\end{tabular}

Figure 16 shows the average Sharpe ratios of both funds and their respective regional market indices. From this figure, it is apparent that funds and market indices from all the included regions behaved similarly across the three phases. None of the regional funds or benchmarks indicates significantly better performance than any other during or post financial crisis. Asian funds, however, performed better, on average, shortly prior to the crisis but also performed the worst, on average, during the crisis period (Figure 16a).
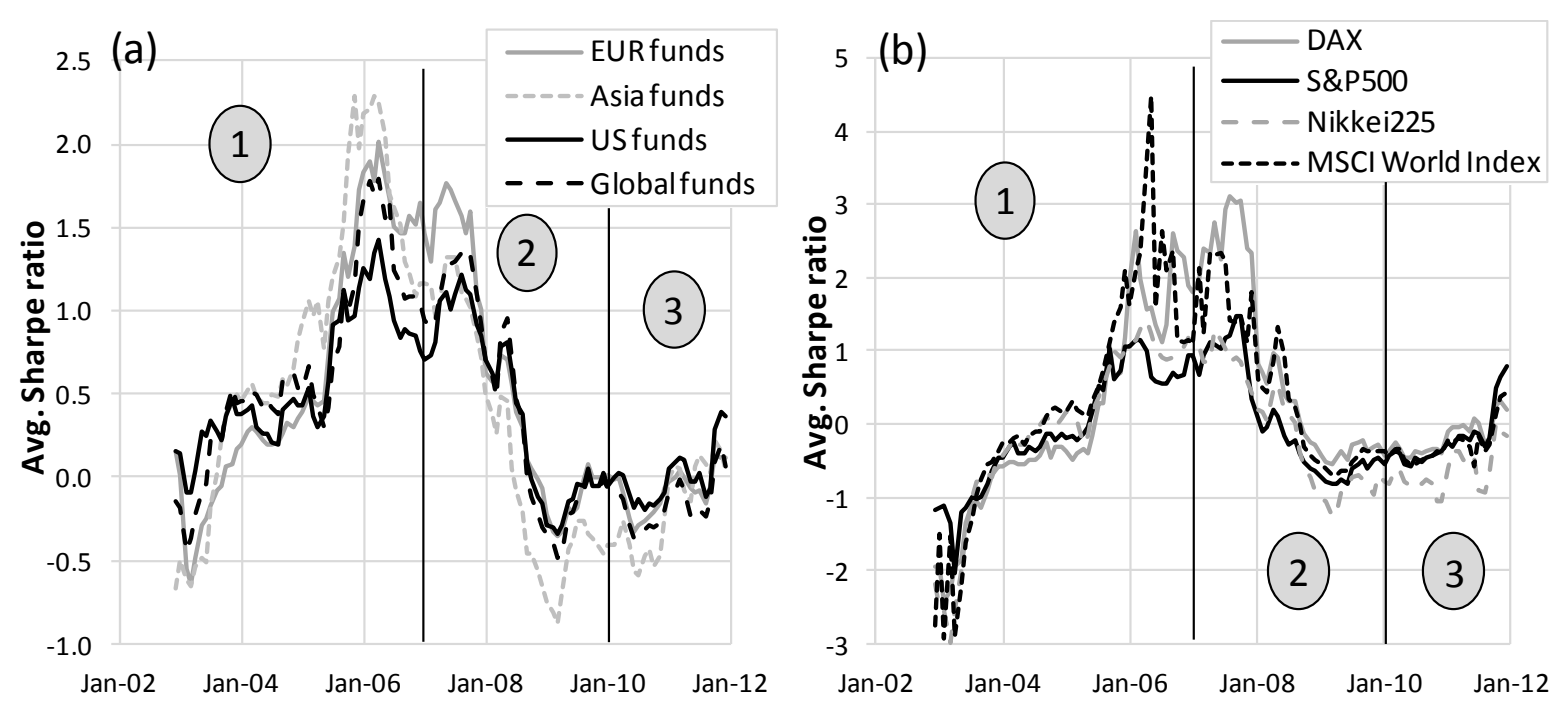

Figure 16: (a) Average Fund Sharpe Ratios per Region and (b) Average Market Index Sharpe Ratios, Through Time

The summary statistics in terms of returns, Bias and Sharpe ratios for the funds grouped by regional mandates are presented in Table 8 to facilitate comparisons. Table 9 presents the corresponding summary statistics for the relevant regional market benchmarks. 
Table 8: Summary Statistics for Regionally Grouped Hedge Funds per Phase

\begin{tabular}{|c|c|c|c|c|c|c|c|c|c|}
\hline & Phase 1 & Phase 2 & Phase 3 & Phase 1 & Phase 2 & Phase 3 & Phase 1 & Phase 2 & Phase 3 \\
\hline & \multicolumn{3}{|c|}{ Return Statistics } & \multicolumn{3}{|c|}{ Bias Ratio Statistics ${ }^{*}$} & \multicolumn{3}{|c|}{ Sharpe Ratio Statistics } \\
\hline \multicolumn{10}{|c|}{ North American Hedge Funds } \\
\hline$n$ & 4165 & 3060 & 2040 & 4165 & 3060 & 2040 & 4165 & 3060 & 2040 \\
\hline$\mu$ & $10.52 \%$ & $6.90 \%$ & $3.45 \%$ & 1.76 & 1.98 & 1.58 & 0.57 & 0.41 & -0.001 \\
\hline$\sigma$ & $11.16 \%$ & $10.15 \%$ & $9.11 \%$ & 0.98 & 1.15 & 0.71 & 0.94 & 0.85 & 0.55 \\
\hline Median & $9.61 \%$ & $7.61 \%$ & $2.42 \%$ & 1.50 & 1.70 & 1.45 & 0.49 & 0.32 & -0.07 \\
\hline Min & $-44.96 \%$ & $-48.39 \%$ & $-36.57 \%$ & 0.29 & 0.26 & 0.25 & -2.35 & -1.61 & -1.92 \\
\hline Max & $59.50 \%$ & $36.52 \%$ & $68.29 \%$ & 8.00 & 8.00 & 7.00 & 4.71 & 4.39 & 4.12 \\
\hline \multicolumn{10}{|c|}{ European Hedge Funds } \\
\hline$n$ & 1862 & 1368 & 912 & 1862 & 1368 & 912 & 1862 & 1368 & 912 \\
\hline$\mu$ & $8.30 \%$ & $7.23 \%$ & $1.52 \%$ & 2.23 & 2.01 & 1.28 & 0.65 & 0.58 & -0.08 \\
\hline$\sigma$ & $9.49 \%$ & $9.20 \%$ & $6.68 \%$ & 1.66 & 1.08 & 0.43 & 1.19 & 1.04 & 0.56 \\
\hline Median & $7.42 \%$ & $7.17 \%$ & $1.98 \%$ & 1.67 & 1.75 & 1.22 & 0.51 & 0.41 & -0.11 \\
\hline Min & $-23.33 \%$ & $-16.56 \%$ & $-18.82 \%$ & 0.39 & 0.70 & 0.37 & -2.90 & -1.59 & -2.19 \\
\hline Max & $42.97 \%$ & $37.65 \%$ & $32.60 \%$ & 8.00 & 8.00 & 3.14 & 5.07 & 4.15 & 2.40 \\
\hline \multicolumn{10}{|c|}{ Asian Hedge Funds } \\
\hline$n$ & 735 & 540 & 360 & 735 & 540 & 360 & 735 & 540 & 360 \\
\hline$\mu$ & $11.32 \%$ & $3.73 \%$ & $-1.11 \%$ & 1.47 & 1.78 & 1.32 & 0.83 & 0.19 & -0.19 \\
\hline$\sigma$ & $11.07 \%$ & $11.58 \%$ & $7.15 \%$ & 0.61 & 1.03 & 0.46 & 1.04 & 1.01 & 0.61 \\
\hline Median & $10.31 \%$ & $3.46 \%$ & $-0.53 \%$ & 1.37 & 0.45 & 0.25 & 0.77 & 0.13 & -0.11 \\
\hline Min & $-16.67 \%$ & $-22.70 \%$ & $-18.10 \%$ & 0.44 & 0.73 & 0.56 & -2.11 & -1.95 & -2.30 \\
\hline Max & $43.61 \%$ & $42.39 \%$ & $14.73 \%$ & 3.60 & 7.67 & 3.00 & 4.28 & 2.88 & 1.13 \\
\hline \multicolumn{10}{|c|}{ Global Hedge Funds } \\
\hline$n$ & 2254 & 1656 & 1104 & 2254 & 1656 & 1104 & 2254 & 1656 & 1104 \\
\hline$\mu$ & $11.66 \%$ & $7.51 \%$ & $2.29 \%$ & 1.54 & 1.85 & 1.40 & 0.66 & 0.44 & -0.16 \\
\hline$\sigma$ & $11.31 \%$ & $10.42 \%$ & $8.22 \%$ & 0.68 & 0.79 & 0.56 & 1.05 & 0.89 & 0.46 \\
\hline Median & $11.47 \%$ & $7.67 \%$ & $2.83 \%$ & 1.44 & 1.71 & 1.38 & 0.59 & 0.30 & -0.18 \\
\hline Min & $-29.69 \%$ & $-33.59 \%$ & $-24.35 \%$ & 0.31 & 0.53 & 0.32 & -3.79 & -1.79 & -2.07 \\
\hline Max & $52.70 \%$ & $38.64 \%$ & $74.64 \%$ & 6.67 & 7.33 & 4.75 & 4.73 & 3.26 & 1.82 \\
\hline
\end{tabular}

The mean of both returns and the Sharpe ratios decline moving through phase 1 to phase 3 (see Table 8). The mean Bias ratios for all regions except Europe increase from phase 1 to phase 2, but then fascinatingly decrease to their lowest levels through all phases in phase 3 - this is not the case for the mean Sharpe ratios. The same pattern is portrayed by the standard deviation of the Bias ratios. Also worth noting is that mean Asian hedge fund returns did not increase into positive territory from phase 2 to phase 3 as the funds from the other regional mandates did (see $\mu$ and median for returns in Table 8). This phenomenon is again echoed for the Asian market as represented by the Nikkei 225 in Table 9. Weighing up the mean returns for the hedge funds per region against their relevant market benchmark indicate that although these funds did not perform very well in absolute terms, they did outperform their respective markets in phase 3 - this was not the case during the crisis (phase 2). During phase 1, all the funds outperformed their respective market benchmarks in terms of return performance. The mean Sharpe ratios of particularly phase 3 of Tables 8 and 9 highlight that at times it could have served investors better to hold riskless assets rather than investments in these funds or even a basket of the market index. 
Table 9: Summary Statistics for Market Indices per Phase

\begin{tabular}{|c|c|c|c|c|c|c|c|c|c|}
\hline & Phase 1 & Phase 2 & Phase 3 & Phase 1 & Phase 2 & Phase 3 & Phase 1 & Phase 2 & Phase 3 \\
\hline & \multicolumn{3}{|c|}{ Return statistics } & \multicolumn{3}{|c|}{ Bias ratio statistics $^{*}$} & \multicolumn{3}{|c|}{ Sharpe ratio statistics } \\
\hline$n$ & 49 & 36 & 24 & 49 & 36 & 24 & 49 & 36 & 24 \\
\hline \multicolumn{10}{|c|}{ US Market Index - S\&P500 } \\
\hline$\mu$ & $-1.54 \%$ & $9.14 \%$ & $-1.80 \%$ & 1.62 & 2.27 & 1.90 & 0.0002 & 0.84 & -0.18 \\
\hline$\sigma$ & $19.17 \%$ & $13.29 \%$ & $5.63 \%$ & 0.48 & 0.47 & 0.62 & 1.34 & 1.30 & 0.233 \\
\hline Median & $-6.02 \%$ & $10.91 \%$ & $-3.62 \%$ & 1.60 & 2.25 & 1.59 & -0.39 & 0.36 & -0.26 \\
\hline Min & $-31.68 \%$ & $-12.80 \%$ & $-9.35 \%$ & 0.82 & 1.50 & 1.30 & -2.41 & -0.56 & -0.46 \\
\hline $\operatorname{Max}$ & $35.05 \%$ & $26.51 \%$ & $9.25 \%$ & 2.83 & 3.40 & 3.40 & 2.64 & 3.12 & 0.32 \\
\hline \multicolumn{10}{|c|}{ European Market Index - DAX } \\
\hline$\mu$ & $0.86 \%$ & $9.14 \%$ & $-1.80 \%$ & 1.33 & 2.60 & 1.76 & -0.08 & 0.05 & -0.23 \\
\hline$\sigma$ & $9.75 \%$ & $13.29 \%$ & $5.63 \%$ & 0.48 & 0.61 & 0.25 & 0.79 & 0.77 & 0.36 \\
\hline Median & $1.82 \%$ & $10.91 \%$ & $-3.62 \%$ & 1.15 & 2.54 & 1.70 & -0.16 & -0.20 & -0.33 \\
\hline Min & $-17.28 \%$ & $-12.80 \%$ & $-9.35 \%$ & 0.62 & 1.62 & 1.23 & -2.04 & -0.82 & -0.59 \\
\hline Max & $15.14 \%$ & $26.51 \%$ & $9.25 \%$ & 2.25 & 4.00 & 2.25 & 1.15 & 1.49 & 0.78 \\
\hline \multicolumn{10}{|c|}{ Asian Market Index - Nikkei 225} \\
\hline$\mu$ & $1.77 \%$ & $-1.07 \%$ & $-11.29 \%$ & 0.93 & 1.51 & 0.93 & -0.09 & 0.06 & -0.64 \\
\hline$\sigma$ & $15.69 \%$ & $14.41 \%$ & $5.90 \%$ & 0.26 & 0.45 & 0.27 & 1.13 & 0.77 & 0.29 \\
\hline Median & $1.29 \%$ & $3.18 \%$ & $-12.40 \%$ & 0.89 & 1.48 & 0.89 & 0.002 & -0.17 & -0.72 \\
\hline Min & $-26.81 \%$ & $-22.41 \%$ & $-19.73 \%$ & 0.57 & 0.86 & 0.56 & -2.98 & -0.82 & -1.07 \\
\hline Max & $29.24 \%$ & $17.25 \%$ & $1.57 \%$ & 1.50 & 2.71 & 1.50 & 1.43 & 1.49 & 0.03 \\
\hline \multicolumn{10}{|c|}{ Global Market Index - MSCI World } \\
\hline$\mu$ & $6.42 \%$ & $4.95 \%$ & $-3.46 \%$ & 1.69 & 2.48 & 2.10 & 0.29 & 0.52 & -0.28 \\
\hline$\sigma$ & $12.43 \%$ & $12.88 \%$ & $6.37 \%$ & 0.70 & 0.55 & 0.36 & 1.56 & 1.04 & 0.26 \\
\hline Median & $8.08 \%$ & $10.02 \%$ & $-4.66 \%$ & 1.62 & 2.33 & 2.12 & 0.17 & 0.38 & -0.35 \\
\hline Min & $-13.36 \%$ & $-16.59 \%$ & $-11.89 \%$ & 0.64 & 1.89 & 1.50 & -2.93 & -0.69 & -0.56 \\
\hline Max & $27.41 \%$ & $20.99 \%$ & $12.29 \%$ & 3.25 & 4.00 & 2.71 & 4.48 & 2.33 & 0.42 \\
\hline
\end{tabular}

\section{SUMMARY AND CONCLUSION}

The Sharpe ratio was supplemented with the Bias ratio as a performance measure in the fund hedge context as the Sharpe ratio is, for instance, influenced by both illiquidity and returns smoothing. 'Live', individual, long/short, equity hedge funds, sourced from the Eurekahedge database covering the period January 2000 to December 2011 and spanning geographical mandates that included North America, Europe, Asia, and global were used. In order to correct for non-IID errors a Sharpe ratio annualisation method that considers the serial correlation of returns was used - the study presents comparative summary statistics between the different methods of computing annualised Sharpe ratio. In terms of methodology this study used a 36-month rolling (window) period to estimate the relevant statistics and ratios.

Even though the Bias ratio has gained some acceptance since its introduction in 2006, a known fraud case was required to confirm that the Bias ratio is indeed a convincing measure of fraud detection, or rather a red flag indicator of possible fraudulent behaviour. The Madoff Ponzi scheme was the chosen case - this case has been used in other Bias ratio related studies, and the Bias ratio was confirmative in these studies (e.g., Douady et al., 2009). The Bias ratio largely confirmed possible suspicious or fraudulent behaviour as estimated from monthly returns of one of the largest Madoff feeder funds, Fairfield Sentry Ltd (FFS). Also, by studying the moments of FFS's returns distribution to those of the relevant market (S\&P500) some out of the ordinary characteristic or patterns were identified that can be thought of as potential warning signals of fraudulent or suspicious behaviour.

Using the identified warning signals from the Madoff case two funds from the funds sample were identified that exhibited similar out of the ordinary characteristics. These warning signals, for both the Madoff case as well as the two identified funds, were presented graphically and in brief comprise: (i) seldom negative mean returns with minimal variation of the mean return; (ii) standard deviation of returns that are significantly lower than that of the relevant market and also shows minimal variation; (iii) returns distribution skewness that is much less volatile compared to that of the relevant market, and also seldom negative skewness; (iv) returns distribution kurtosis that 
behaves in an anti-correlated manner to that of the market; (v) a Bias ratio that behaves in an opposite fashion to that the market; and (vi) a Sharpe ratio that is almost always higher than that of the market and also almost never negative. In addition, abnormally high Sharpe ratios compared to similar funds are also a cause for suspicion. Essentially, the identified characteristics emphasise that return characteristics that are dissimilar to those of the relevant market should be thought of as warning signals of possible fraudulent activity.

The first of the three results sections (see Section 4.1) illustrated how ill-suited the Sharpe ratio is for (these) hedge fund return data, or how inaccurate (these) hedge fund data are for use with the Sharpe ratio. This section confirmed the Sharpe ratio's ill-suitedness by focusing on the normality of the return distributions (JB-test) and the return distributions' higher moments from both a static and 36-month rolling perspective. Results indicate that return distributions moved further from normal(ity) during the crisis period (December 2006 - December 2009) while kurtosis increased and skewness turned negative, both dramatically, during this period.

The final results section aimed to highlight the changing characteristics of hedge funds and their respective market benchmarks over the varying economic conditions around the 2007 financial crisis, and thus a selective statistical analysis of returns was conducted. Results indicate a decrease in the average return as well as a simultaneous increase in volatility across all funds during the crisis period with average Sharpe ratios often falling below zero. Average mean Bias ratios increase from pre-to during the crisis where after it decreases in the period post the crisis to its lowest levels throughout the three phases. Geographically, it was found that funds and market indices from all included regions behave similarly across the three phases and none of the regional funds or benchmarks indicates significantly better performance than another during or post the financial crisis. In the period prior to the crisis Asian funds performed better, on average. For market indices, an immediate increase in risk after the onset of the financial crisis was observed: North American and European markets (indices) were less risky during the crisis period compared to those in Asia and globally. Hedge funds from all regions outperformed their relevant market indices prior to the crisis.

The need to accurately distinguish between poor and good quality fund returns has not diminished, and in actual fact is ever increasing. Higher moments of the return distributions must be accounted for if accurate fund comparisons (in terms of risk-adjusted returns) are desired.

The Bias ratio, though not a perfect measure, presents firm and encouraging arguments that a measure that detects or red flags potential fraudulent or suspicious behaviour should augment the use of the Sharpe ratio. Not only does the Bias ratio consider a risk dimension that is not considered by the Sharpe ratio, but the Sharpe ratio is also influenced by fraudulent behaviour such as returns smoothing that may be flagged by a measure such as the Bias ratio. In essence, measures that account for moments of the returns distribution structure not considered by the Sharpe ratio will prove valuable to investors and such measures should arguably be considered to supplement the use of the Sharpe ratio. The latter will also enhance the justified call for greater transparency concerning hedge fund performance and reporting.

Exploring and comparing alternative fraud measures and using a suitable ranking methodology to compare fund rankings of the Sharpe and Bias ratios will undeniably contribute to the research areas of hedge fund fraud, behaviour and performance.

\section{ACKNOWLEDGEMENTS}

This work is based on research financially supported by the National Research Foundation (NRF) along with the University of South Africa. Any opinion, finding, and conclusion or recommendation expressed in this material is that of the author(s): the NRF and the University of South Africa do not accept any liability in this regard.

The Workwell Research Unit at the North-West University, Potchefstroom, South Africa, for their financial assistance in procuring the data. 


\section{AUTHOR INFORMATION}

Francois van Dyk began his career as a risk analyst specialising in Basel II at FirstRand Bank Ltd., in South Africa. He furthered his career as a senior consultant at a niche international risk consultancy. He currently holds a senior lecturing position at the University of South Africa. This study forms part of his $\mathrm{PhD}$ in risk management at the North-West University (Potchefstroom campus) which focuses on novel, quantitative risk measures within a hedge fund context. He obtained his Masters in risk, focusing on investment portfolio risk, cum laude, He holds a PRM and CHP and is currently pursuing his CFA qualification. E-mail: vdykf@unisa.ac.za (Corresponding author)

Gary van Vuuren began his career with a Masters in astrophysics and a $\mathrm{PhD}$ in nuclear physics. He transferred to quantitative finance and, after a spell at Goldman Sachs in London, obtained a Masters in market risk and a PhD in credit risk. He then worked as a risk manager for South African retail banks and asset managers before moving to London and working in retail and investment banks. He settled on quantitative risk assessment and management in financial institutions for Fitch Ratings where he remains employed. He is an accredited GARP Financial Risk Manager. E-mail: vvgary@ hotmail.com

André Heymans. After completing his $\mathrm{PhD}$ in finance in 2007, André Heymans moved to London where he was employed by BNY MELLON until the middle of 2008. He then moved to South Africa to fill the position of Head: Research and Development in the trading room at an agricultural trading firm (Free State Maize). André moved back to academia in April 2009 where he currently holds the position Program Head of Risk Management. E-mail: andre.heymans@nwu.ac.za

\section{REFERENCES}

1. Abdulali, A. (2006). The bias ratio: Measuring the shape of fraud. Protégé Partners Quarterly Letter, $3^{\text {rd }}$ Quarter.

2. Ackermann, C., Mcenally, R., \& Ravenscraft, D. (1999). The performance of hedge funds: Risk, returns and Incentives. Journal of Finance, 54(3), 833-874.

3. Agarwal, V., \& Naik, N. Y. (2004). Risk and portfolio decisions involving hedge funds. Review of Financial Studies, 17(1), 63-98.

4. Agarwal, V., Daniel, N. D., \& Naik, N. Y. (2011). Do hedge funds manage their reported returns? The Review of Financial Studies, 24(10), 3281-3320.

5. Barclayhedge (2013). [Online] Retrieved 29 June 2013 from http://www.barclayhedge.com/research/ indices/ghs/mum/Hedge_Fund.html

6. Bisias, D., Flood, M., Lo, A. W., \& Valavanis, S. (2012). A survey of systemic risk analytics. Annual Review of Financial Economics, 4(1), 255-296.

7. Bollen, N. P. B., \& Pool, V. K. (2008). Conditional return smoothing in the hedge fund industry. Journal of Financial and Quantitative Analysis, 43(2), 267-298.

8. Bollen, N. P. B., \& Pool, V. K. (2009). Do hedge fund managers misreport returns? Evidence from the pooled distribution. Journal of Finance, 64(5), 2257-2288.

9. Bollen, N. P. B., \& Pool, V. K. (2012). Suspicious patterns in hedge fund returns and the risk of fraud. Review of Financial Studies, Forthcoming.

10. Botha, M. (2007). A comparison of South African hedge fund risk measures. South African Journal of Economics, 75(3), 459-477.

11. Brooks, C., \& Kat, H. (2003). Stocks, bonds and hedge funds: Not a free lunch. Journal of Portfolio Management, 29(4), 113-120.

12. Brown, S. J., Kacperczyk, M., Ljungqvist, A., Lynch, A., Pedersen, L., \& Richardson, M. (2009). Hedge funds in the aftermath of the financial crisis. Financial Markets, Institutions \& Instruments, 18(2), 155-156.

13. Brown, S. J., Goetzmann, W. N., \& Ibbotson, R. G. (1999). Offshore hedge funds: Survival and performance 1989-1995. Journal of Business, 72(1), 91-118.

14. Brown, S. J., Goetzmann, W. N., \& Park, J. (2001b). Careers and survival: competition and risk in the hedge fund and CTA industry. Journal of Finance, 56(5), 1869-1886.

15. Brown, S. J., Goetzmann, W. N., Hiraki, T., Otsuki, T., \& Shiraishi, N. (2001a). The Japanese open-end fund puzzle. Journal of Business, 74(1), 59-78. 
16. Brown, S. J., Kang, M., In, F. H., \& Lee, G. (2010). Resisting the manipulation of performance metrics: An empirical analysis of the manipulation-proof performance measure. (Working paper). Retrieved 15 Dec. 2012 from http://papers.ssrn.com/sol3/papers.cfm?abstract_id=1536323

17. Cao, C., Farnsworth, G. V., Liang, B., \& Lo, W. A. (2013). Liquidity costs, returns smoothing, and investor flows: Evidence from a spate account platform. (Working paper). Retrieved 10 Oct. 2013 from http://papers.ssrn.com/sol3/papers.cfm?abstract_id=2269901

18. Chan, N., Getmansky, M., Haas, S. M., \& Lo, A. W. (2005). Systemic risk and hedge funds. Optimization, 920(617), 235-338.

19. Cici, G., Kempf, A., \& Pütz, A. (2013). The valuation of hedge funds' equity positions. (CFR Working paper). Retrieved 11 Oct. 2013 from http://papers.ssrn.com/sol3/papers.cfm?abstract_id=1664461

20. CITI. (2012). Hedge fund industry snapshot. April. Retrieved 19 Feb. 2013 from http://icg.citi.com/icg/ global_markets/prime_finance/docs/hf_monthly_apr12_primefin.pdf

21. Clarke, W. (2012). Hedge fund launches still below their pre-crisis peak. Investment Europe. 15 March. Retrieved 3 March 2013 from http://www.investmenteurope.net/investment-europe/news/2159709/hedgefund-launches-pre-crisis-peak

22. Damodaran, A. (2008). What is the riskfree rate? A search for the basic building block. (Working paper). Retrieved 15 March 2013 from http://papers.ssrn.com/sol3/papers.cfm?abstract_id=1317436

23. Do, V., Faff, R., \& Wickramanayake, J. (2005). An empirical analysis of hedge fund performance: The case of Australian hedge funds industry. Journal of Multinational Financial Management, 15(4-5), 377393.

24. Doerig, H. U. (2003). Operational risk in financial services: an old challenge in a new environment. Credit Suisse Group. Presented IIEB, London Oct. 2000. Retrieved 3 March 2013 from https://www.creditsuisse.com/governance/doc/operational_risk.pdf

25. Douady, R., Abdulali, A., \& Adlerberg, I. (2009). The Madoff case: Quantitative bests qualitative. Retrieved 20 Nov. 2013 from http://www.riskdata.com/resources/hedge_funds_risk_and_replication.html

26. Dowd, K. (2000). Adjusting for risk: An improved Sharpe ratio. International Review of Economics and Finance, 9(3), 209-222.

27. Eurekahedge. (2010). 2010 key trends in global hedge funds. Hedge Fund Monthly, August. Retrieved 23 Feb. 2013 from http://www.eurekahedge.com/news/10_aug_EH_Aug-10_GHF_Key_Trends_ABR.asp

28. Eurekahedge. (2012). 2012 key trends in global hedge funds. Hedge Fund Monthly, July. Retrieved 19 Feb. 2013 from http://www.eurekahedge.com/news/Eurekahedge_Jul_2012_Global_Hedge_Funds_Key_ Trends.asp

29. Eurekahedge. (2013). The Eurekahedge report. June. Retrieved 19 June 2013 from http://www.eurekahedge.com/news/13_jun_Eurekahedge_Report_online.asp

30. Feng, S. (2011). Three essays on hedge fund fee structure, return smoothing and gross performance. Amherst: University of Massachusetts. (Dissertation - D.Phil). Retrieved 3 March 2013 from http://scholarworks.umass.edu/open_access_dissertations/461/

31. Fung, W., \& Hsieh, D. A. (1997). Empirical characteristics of dynamic trading strategies: The case of hedge funds. Review of Financial Studies, 10(2), 275-302.

32. Fung, W., \& Hsieh, D. A. (2001). The risk in hedge funds strategies: theory and evidence from trend followers. Review of Financial Studies, 14(2), 313-341.

33. Fung, W., \& Hsieh, D. A. (2004). Hedge fund benchmarks: A risk based approach. Financial Analysts Journal, 60(5), 65-80.

34. Getmansky, M., Lo, A., \& Makarov, I. (2004). An econometric analysis of serial correlation and illiquidity in hedge fund returns. Journal of Financial Economics, 74(3), 529-609.

35. Gibbons, M., Ross, S., \& Shanken, J. (1989). A test of the efficiency of a given portfolio. Econometrica, 57(5), 1121-1152.

36. Goetzmann, W., Ingersoll, J., \& Spiegel, M. (2007). Portfolio performance manipulation and manipulationproof performance measures. Review of Financial Studies, 20(5), 1503-1546.

37. Goetzmann, W., Ingersoll, J., Spiegel, M., \& Welch, I. (2002). Sharpening Sharpe ratios. (Working paper). NBER.

38. Gregoriou, G. N., \& Geuyie, J. P. (2003). Risk-adjusted performance of funds of hedge funds using a modified Sharpe ratio. Journal of Wealth Management, 6(3), 77-83. 
39. In, F. (2009). A new approach to detect suspicious funds. (Discussion paper). Australian Centre for Financial Studies. Retrieved 15 Nov. 2012 from http://www.melbournecentre.com.au/ ResearchGrantProgram.html

40. Jobson, J. D., \& Korkie, B. M. (1981). Performance hypothesis testing with the Sharpe and Treynor measures. Journal of Finance, 36(4), 889-908.

41. Kaiser, D., \& Haberfelner, F. (2012). Hedge fund biases after the financial crisis. Managerial Finance, 38(1), 27-43.

42. Kaplan, P. D., \& Knowles, J. A. (2004). Kappa: A generalized downside risk-adjusted performance measures. Journal of Performance Measurement, 8(3), $42-54$.

43. Kat, H. M., \& Amin, G. S. (2001). Welcome to the dark side: Hedge fund attrition and survivorship bias over the period 1994-2001. (Working paper). Retrieved 1 March 2013 from http://papers.ssrn.com/sol3/ papers.cfm?abstract_id=293828

44. Koekebakker, S., \& Zakamouline, V. (2008). Generalized Sharpe ratios and portfolio performance evaluation. (Working paper). Retrieved 12 Dec. 2012 from http://papers.ssrn.com/sol3/ papers.cfm?abstract_id $=1028715$

45. Le Marois, O. (2008). Return smoothing practices: A potential threat for alternative investment growth. Retrieved 11 Oct. 2013 from http://www.riskdata.com/resources/hedge_funds_risk_and_replication.html

46. Leland, H. E. (1999). Beyond mean-variance: Risk and performance measurement in a nonsymmetrical world. Financial Analysts Journal, 55(1), 27-36.

47. Leung, P., \& Wong, W. K. (2007). On testing the equality of the multiple Sharpe ratios, with application on the evaluation of iShares. (Working paper). Retrieved 26 Feb. 2013 from ied.hkbu.edu.hk/publications/ fdp/FDP200803.pdf

48. Levy, H. (1972). Portfolio performance and investment horizon. Management Science, 8(12), 645-653.

49. Lhabitant, F. (2004). Hedge funds: Quantitative insight. Haboken, NJ: Wiley.

50. Liang, B. (1999). On the performance of hedge funds. Financial Analysts Journal, 55(4), 72-85.

51. Ljung, G. M., \& Box, G. E. P. (1978). On a measure of a lack of fit in time series models, Biometrika, 65(2), 297-303.

52. Lo, A. W. (2001). Risk management for hedge funds: Introduction and overview. Financial Analysts Journal, 57(6), 16-33.

53. Lo, A. W. (2002). The statistics of Sharpe Ratios. Financial Analysis Journal, 58(4), 36-52.

54. Lopez De Prado, M. (2013). How long does it take to recover from a drawdown? (Working paper). Retrieved 11 Oct. 2013 from http://papers.ssrn.com/sol3/papers.cfm?abstract_id=2254668

55. Malkiel, B. G., \& Saha, A. (2005). Hedge funds: Risk and return. Financial Analysts Journal, 61(6), 80-88.

56. Maller, R. A., \& Turkington, D. A. (2002). Mathematical methods of operations research. Mathematical Methods of Operations Research, 56(3), 501-511.

57. Memmel, C. (2003). Performance hypothesis testing with the Sharpe Ratio. Finance Letters, 1(1), 21-23.

58. Nigrini, M. J., \& Mittermaier. (1997). The use of Benford's law as an aid in analytical procedures. Auditing: A Journal of Practice and Theory, 16(2), 5267.

59. Nigrini, M. J. (1999). I've got your number. Journal of Accountancy, May.

60. Opdyke, J. D. (2007). Comparing Sharpe ratios: So where are the p-values? Journal of Asset Management, 8(5), 308-336.

61. Patton, A. J., Ramadorai, T., \& Streatfield, M. (2012). Change you can believe in? Hedge fund data revisions. (CEPR Discussion Paper). Retrieved 11 April 2013 from http://www.cepr.org/ pubs.dps.DP8898.asp

62. Perello, J. (2007). Downside risk analysis applied to hedge funds universe. Retrieved 4 July 2013 from http://arxiv.org/pdf/physics/0610162v2.pdf

63. Raimi, R. (1976). The first digit problem. American Mathematical Monthly, 83(7), 521-538.

64. Roxburgh, C., Lund, S., Lippert, M., White, O. L., \& Zhao, Y. (2009). The new power brokers: How oil, Asia, hedge funds, and private equity are faring in the financial crisis. McKinsey \& Company Report. July. Retrieved 23 Feb. 2013 from http://www.mckinsey.com/insights/economic_studies/how_the_new_power_ brokers_are_faring_in_financial_crisis

65. Schmid, F., \& Schmidt, R. (2007). Statistical inference for Sharpe's Ratio. (Working paper). Retrieved 27 Feb. 2013 from http://wifo4.bwl.unimannheim.de/fileadmin/files/hws10/Schmid_Schmidt_Statistical_ Inference.pdf 
66. Scott, R. C., \& Horvath, P. A. (1980). On the direction of preferences for moments of higher order than the variance. Journal of Finance, 35(4), 915-919.

67. Shadwick, W. F., \& Keating, C. (2002). A universal performance measure. Journal of Performance Measurement, 6(3), 59-87.

68. Sharpe, W. F. (1966). Mutual fund performance. The Journal of Business, 39(1), 119-138.

69. Sharpe, W. F. (1975). Adjusting for risk in portfolio performance measurement. Journal of Portfolio Management, 1(2), 29-34.

70. Sharpe, W. F. (1992). Asset allocation: Management style and performance measurement. Journal of Portfolio Management, 18(2), 7-19.

71. Sharpe, W. F. (1994). The Sharpe ratio. Journal of Portfolio Management, 21(1), 49-58.

72. Sortino, F. A., \& Price, L. N. (1994). Performance measurement in a downside risk framework. Journal of Investing, 3(3), 59-65.

73. Spurgin, R. B. (2001). How to game your Sharpe ratio. Journal of Alternative Investments, 4(3), 38-46.

74. Stutzer, M. (2000). A portfolio performance index. Financial Analysts Journal, 56(3), 52-61.

75. The Economist. (2013). Trimmed hedges. April 6. Retrieved 11 April 2013 from http://www.economist.com/news/finance-and-economics/21575807-best-not-rely-too-much-glowing-trackrecord-trimmed-hedges

76. Thecityuk. (2012). Global hedge funds see \$70bn net inflow of funds in 2011 as launches outpace liquidations for second year running. Hedge Fund Report 2012. Retrieved 2 March 2013 from http://www.thecityuk.com/media/press-releases/global-hedge-funds-see-70bn-net-inflow-of-funds-in-2011as-launches-outpace-liquidations-for-second-year-running/

77. Vanguard. (2012). Investment risk and financial advice. Retrieved 29 June 2013 from https://www.vanguard.co.uk/documents/adv/literature/investor-risk-profiling.pdf

78. Van Vuuren, G., Botha, M., \& Styger, P. (2003). Tricky business: Measuring risk and return. GARP Risk Review, 15, Nov/Dec. Retrieved 10 Dec. 2012 from http://w.eraider.com/images/articles/Issue15_1.pdf

79. Wiesinger, A. (2010). Risk-adjusted performance measurement: State of the art. St. Gallen: University of St. Gallen. (Bachelor Thesis - BBA). Retrieved 6 June 2013 from http://www.iorcf.unisg.ch/ Forschung/ /media/0D77AF25603347E795C77DDA1DD83676.ashx

80. Ziemba, W. (2005). The symmetric downside-risk sharpe ratio. Journal of Portfolio Management, 32(1), $108-122$. 